\title{
Repeating earthquakes in western Corinth Gulf (Greece): implications for aseismic slip near locked faults
}

\author{
Maria Mesimeri and Vassilios Karakostas \\ Geophysics Department, School of Geology, Aristotle University of Thessaloniki, Thessaloniki 54124, Greece.E-mail: mmesimer@geo.auth.gr
}

Accepted 2018 July 20. Received 2018 July 18; in original form 2018 January 24

\begin{abstract}
SUMMAR Y
An extensive search for repeating earthquakes was performed in the western Corinth Gulf by applying waveform cross-correlation on 22000 earthquakes that occurred in 2008-2014. Event pairs with high correlation coefficient $(C C \geq 0.95)$ recorded by two or more stations are classified as multiplets of repeating events. The highly similar event pairs have typically interevent distances less than a quarter wavelength $(\sim 150 \mathrm{~m}$ for a dominant frequency of $10 \mathrm{~Hz}$ ) and are used to estimate the accuracy of the relocated catalogue. A detailed analysis of the spatio-temporal properties of the repeating sequences revealed two types of repeating events, namely, burst-like and continuous-type repeaters. Burst-like repeaters are widespread in the entire study area, mostly associated with seismic excitations located at depths between 5 and $9 \mathrm{~km}$, triggered either by fluid intrusion or stress transfer. Their duration is short with high values of coefficient of variation in recurrence intervals $(\mathrm{COV}>1)$ and high slip rates. The continuous-type repeaters, which last $1-7 \mathrm{yr}$, with $\mathrm{COV} \sim 1$ and slip rates almost $0.26 \mathrm{~cm} \mathrm{yr}^{-1}$, form a very narrow shallow north-dipping seismic zone at $10 \mathrm{~km}$ depth along the Psathopyrgos and Aigion faults. That kind of activity provides strong evidence for aseismic slip in the western Corinth Gulf and defines the boundary between brittle and ductile layers in the area.
\end{abstract}

Key words: Plasticity, diffusion, and creep; Seismicity and tectonics; Continental tectonics: extensional.

\section{INTRODUCTION}

Repeating earthquakes are events that occur at the same location, with the same source mechanism, and rupture the same area but at different times (Beroza et al. 1995). An attempt to model the triggering mechanism of repeating earthquakes associates their occurrence with aseismic creep on the surrounding fault surface, where microearthquake foci form linear streaks on the boundaries between locked and creeping patches (Beeler et al. 2001; Sammis \& Rice 2001; Johnson \& Nadeau 2002). A more complicated model suggests that an inner asperity is surrounded by a larger creeping zone, which in turn is surrounded by a still larger locked zone (Anooshehpoor \& Brune 2001). The common characteristic in these models is that repeating earthquakes define areas of aseismic slip whereas the rest parts are considered locked.

Repeating earthquakes have been found in areas of well-known creeping faults, such as the San Andreas fault (e.g. Vidale et al. 1994; Nadeau \& Johnson 1998; Nadeau \& McEvilly 1999, 2004; Rubin et al. 1999; Schaff et al. 2002; Waldhauser \& Ellsworth 2002; Nadeau et al. 2004; Waldhauser \& Schaff 2008). The identified streaks of microearthquakes are interpreted as the boundaries of the seismogenic zone between locked patches whereas the shallower parts are creeping. Repeating events were also found below the western part of the Marmara section of the North Anatolia Fault, indicating that this section deforms aseismically, which reduces the probability to host a nucleation point of an upcoming strong earthquake (Bohnhoff et al. 2017). In subduction zones, repeating earthquakes are associated with repeated slips on small asperities surrounded by stable sliding area and can be used as creepmeters (Igarashi et al. 2003; Uchida et al. 2003, 2005; Dominguez et al. 2016; Weston \& Shirzaei 2016). In aftershock sequences, repeating events have been related to afterslip (e.g. Papadimitriou et al. 2017; Yao et al. 2017) or to the presence of rheological discontinuity (e.g. Valoroso et al. 2013). Repeating events were sought in regional scale in China, where it has been shown that their occurrence cannot be related to tectonic loading, mainly due to their short recurrence intervals (Schaff \& Richards 2004, 2011). Human activity, such as mining, is also able to produce strong repeating mining tremors (Rudziński et al. 2017).

Furthermore, the recurrence times of repeating events have been studied aiming to interpret their triggering mechanism. Particularly, when the interevent times between subsequent events have regular intervals, it is assumed that the repeating events occur due to tectonic loading (e.g. Nadeau \& Johnson 1998; Rubinstein et al. 2012). On the other hand, it was found that interevent times in repeating sequences follow the Omori law, indicating a triggering mechanism and a more main-shock-aftershock behaviour (e.g. Schaff et al. 1998). Another factor that influences the recurrence intervals in 


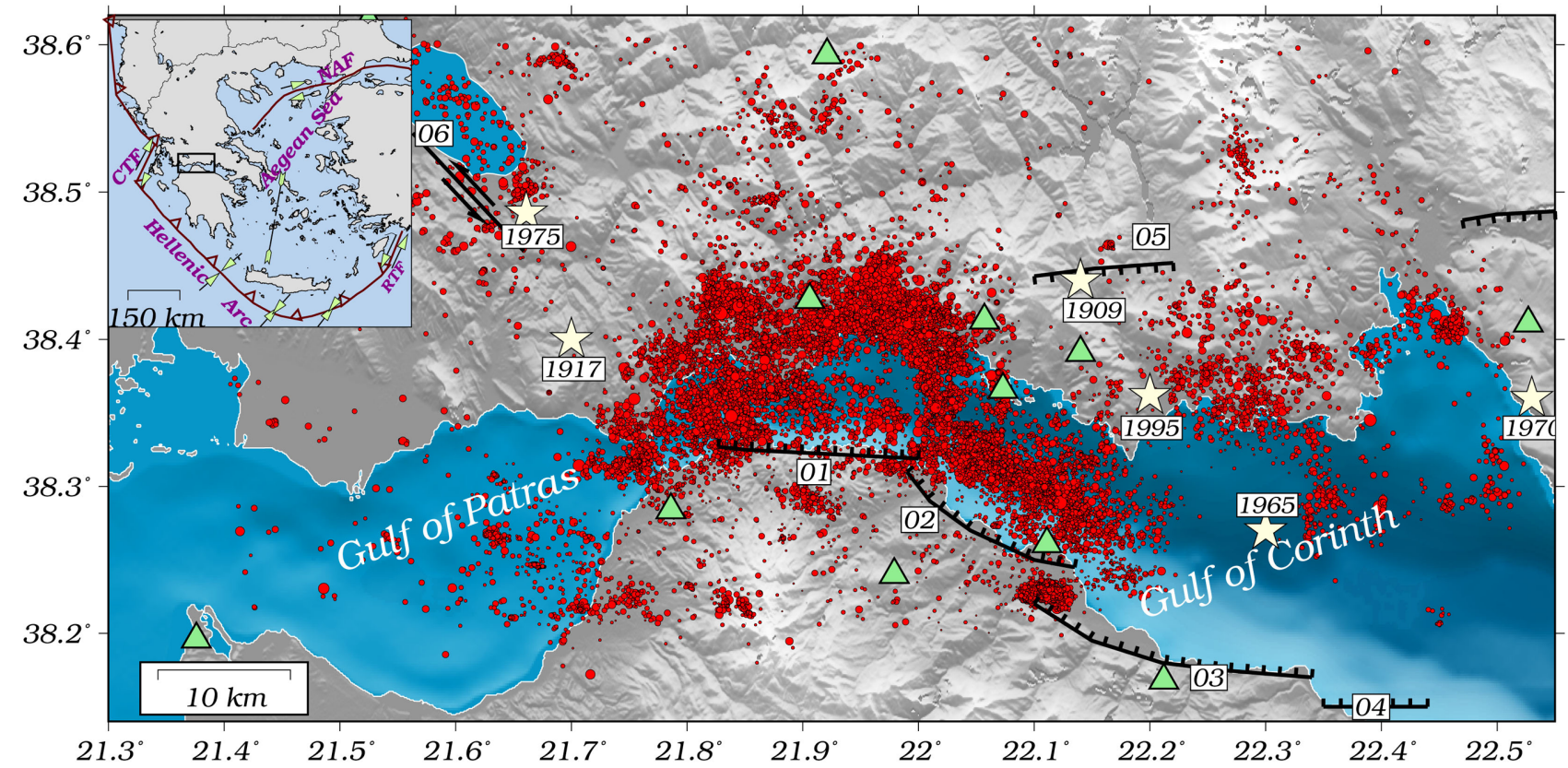

Figure 1. Morphological map of the Corinth Gulf along with fault segments of: 01-Psathopyrgos, 02-Aigion, 03-Heliki, 04-Offshore Akrata, 05-Lidoriki and 06-Trichonida (Armijo et al. 1996; Kiratzi et al. 2008; Console et al. 2013). Earthquakes occurred since 1900 with $M \geq 6.0$ are shown by stars (Papazachos \& Papazachou 2003). Red circles show earthquakes occurred during 2008-2014 (Mesimeri et al. 2018). The stations of the Hellenic Unified Seismological Network are displayed by triangles. Inset map. The backarc Aegean Sea and the surrounding area, with the dominant seismotectonic features, including the Hellenic trench along with the subduction of the East Mediterranean lithosphere under the Aegean, and the North Anatolian Fault (NAF) which accommodates the westward extrusion of the Anatolian plate into the Aegean. The tectonic setting is supplemented with the existence of the Cephalonia (CTF) and Rhodes (RTF) transform faults. The study area is enclosed in the rectangle.
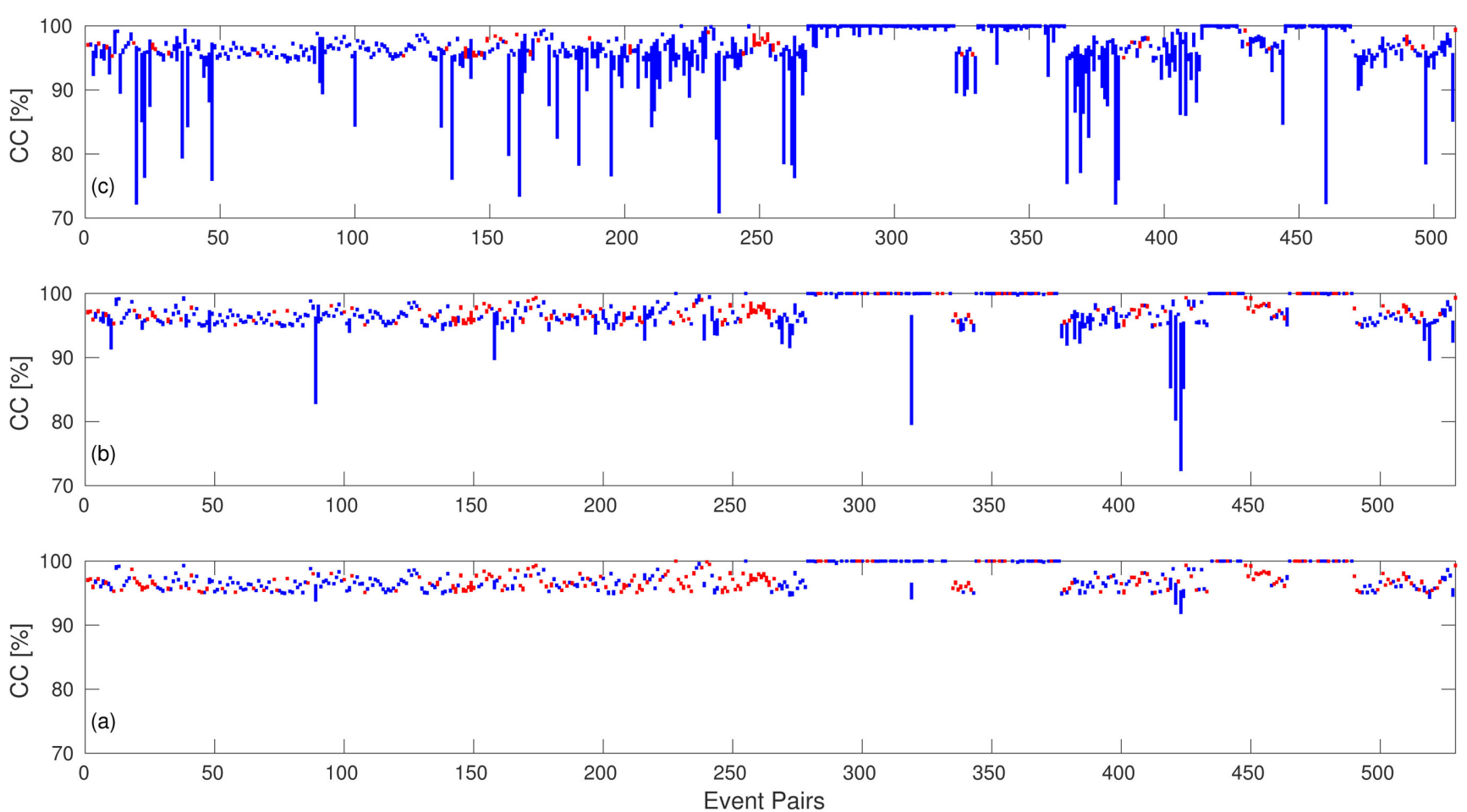

Figure 2. Comparison of the correlation coefficients (CC) between event pairs with at least one earthquake with $M \geq 3.0$, filtered in the band 2.0-10 Hz and the respective pairs filtered in the bands (a) $1.5-10 \mathrm{~Hz}$, (b) $1.0-10 \mathrm{~Hz}$ and (c) $0.5-10 \mathrm{~Hz}$. Blue and red lines indicate positive and negative changes, respectively.

repeating sequences is the uneven distribution of stress changes in time by neighbouring events (Chen et al. 2013). Given that repeating events are ruptures of the same fault patch, they can also provide information about the characteristics of the medium and are used for measuring co-seismic and post-seismic changes in velocity (e.g. Schaff \& Beroza 2004; Kanu et al. 2013).

In this work, the entire waveform database of the western Corinth Gulf(Mesimeri et al. 2018) was searched for multiplets of repeating 


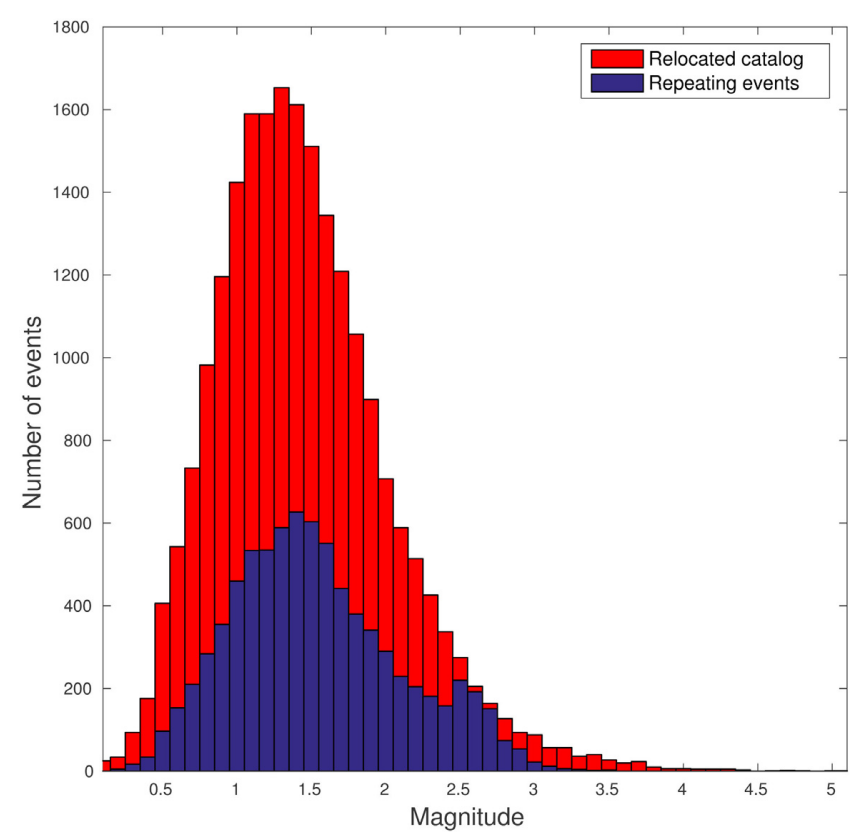

Figure 3. Magnitude distribution of the events in the relocated catalogue (red bars) along with the events that are identified as repeating earthquakes (blue bars).

events by applying waveform cross-correlation in a window that includes almost the entire seismogram. A detailed spatio-temporal analysis is performed along with the estimation of the amount of slip released in each repeating sequence and the investigation of recurrence intervals' regularity. Combining the above, we aim to shed more light on the seismogenesis process in the western Corinth Gulf, deciphering the mechanism of the continuous seismic activity, which forms a very narrow shallow north-dipping zone at $10 \mathrm{~km}$ depth and its differentiation from the burst-like seismic excitations located above this zone.

\section{TECTONIC SETTING}

Corinth Gulf (Fig. 1), located in central Greece, is one of the most seismically active rifts in Europe with the overall shape of an asymmetric half-graben and trending almost WNW-ESE (Armijo et al. 1996). The deformation in the area is high, reaching an extension rate of $1.4 \mathrm{~cm} \mathrm{yr}^{-1}$ (Billiris et al. 1991; Clarke et al. 1998; Briole et al. 2000; Avallone et al. 2004; Chousianitis et al. 2015). A series of major north-dipping faults, having their surface traces along the south coastline, dominate the western part of the Corinth Gulf. Particularly, from west to east, the Psathopyrgos (01), Aigion (02), Heliki (03) and Xylokastro (04) faults (Fig. 1) have lengths between 15 and $25 \mathrm{~km}$, an average strike of $270^{\circ}-285^{\circ}$ and a northward dip (Armijo et al. 1996). Fault plane solutions show normal faults striking almost E-W, in consistency with the rift structure and the geometry of the major faults in the area (Baker et al. 1997; Papazachos et al. 1998).

Several strong earthquakes with $M>6$ (stars in Fig. 1) have struck the broader area of western Corinth Gulf during the instrumental era and caused severe damage in several cities (Papazachos \& Papazachou 2003; Makropoulos et al. 2012). The assessment of the hazard emerging from these frequent strong events has been the target of numerous studies among them being recently the approximation with synthetic catalogues (Console et al. 2015; Mangira et al. 2017). The last strong earthquake with $M=6.5$ occurred on 1995 June 15 and was associated with the Aigion fault (Bernard et al. 1997). Small magnitude earthquakes occur frequently in the area with the vast majority of them being located north of the Aigion fault (Fig. 1). Seismic excitations, strongly clustered both in space and time, occur on small fault segments located at depths between 5 and $9 \mathrm{~km}$ and dipping with an angle of $45^{\circ}-60^{\circ}$ mainly to the north. Continuous microseismic activity was found to form a very narrow shallow north-dipping zone at almost $10 \mathrm{~km}$ depth. The underlying mechanism responsible for the existence of that zone is still debated with two dominant theories attempting to provide a reliable interpretation. The first one associates the shallow-dipping seismic zone with the existence of a detachment zone where all mapped north-dipping faults are rooting and has the geometry of a lowangle north-dipping normal fault (Rigo et al. 1996; Lambotte et al. 2014) whereas the second theory suggests that the microseismicity is probably related to the seismic-aseismic transition (Hatzfeld et al. 2000; Mesimeri et al. 2018).

\section{REPEATING EVENTS}

\subsection{Data and multiplet classification}

In order to search for repeating events we use the waveforms' database and the relocated catalogue obtained by Mesimeri et al. (2018) which covers 7 yr of activity (2008-2014). The database consists of $60 \mathrm{~s}$ waveforms of approximately 22000 events recorded at 55 three-component broad-band stations with sampling rate of 100 samples $\mathrm{s}^{-1}$. Repeating events were sought by performing crosscorrelation in time domain (Schaff et al. 2004; Schaff \& Waldhauser 2005) after applying a bandpass filter $2.0-10 \mathrm{~Hz}$ to the waveforms. Any dependence of the results on the frequency content of the waveforms was tested for the event pairs including at least one earthquake with magnitude $M \geq 3.0$. The resulted correlation coefficients were compared with the ones obtained after filtering the data in different frequency bands (Fig. 2). When the lower filter is $1.5 \mathrm{~Hz}$ the differences are rather negligible, with most of them in the range \pm 1 per cent (Fig. 2a). Almost similar is the distribution of the differences with the lower filter equal to $1.0 \mathrm{~Hz}$ where the 90 per cent of the correlation coefficients remain above 0.95 (Fig. 2b). Only the data obtained after filtering in the frequency band $0.5-10 \mathrm{~Hz}$ show a rather systematic decrease with the 9 per cent of the correlation coefficients to be less than 0.90 (Fig. 2c). It is noteworthy that correlation coefficients with values higher than 0.98 are independent of the frequency content of the waveforms. Since the differentiation is not significant, in frequencies higher than $1.0 \mathrm{~Hz}$ (e.g. Hauksson \& Shearer 2005; Valoroso et al. 2013) or $1.5 \mathrm{~Hz}$ (e.g. Waldhauser $\&$ Schaff 2008), we decided to keep the event pairs obtained by filtering in the frequency band $2-10 \mathrm{~Hz}$.

In this study, we look for similarities in a longer window of the seismogram including both $P$ and $S$ waves. An $8 \mathrm{~s}$ window after $P$ phase arrival and a search $\pm 1 \mathrm{~s}$ around it were chosen after testing several values. All event pairs that have high correlation coefficient $(\mathrm{CC} \geq 0.95)$ are kept. Following the sensu lato definition of Got et al. (1994), an event is considered as a member of a multiplet when it is a doublet with at least one other event in the multiplet. This approach, slightly modified in a few cases, has been used for identifying repeating events in different areas and tectonic environments (Igarashi et al. 2003; Peng \& Ben-Zion 2005; Becker et al. 2006; Schaff \& Richards 2011; Yao et al. 2017). It allows to create larger families of repeating events rather than smaller ones, 

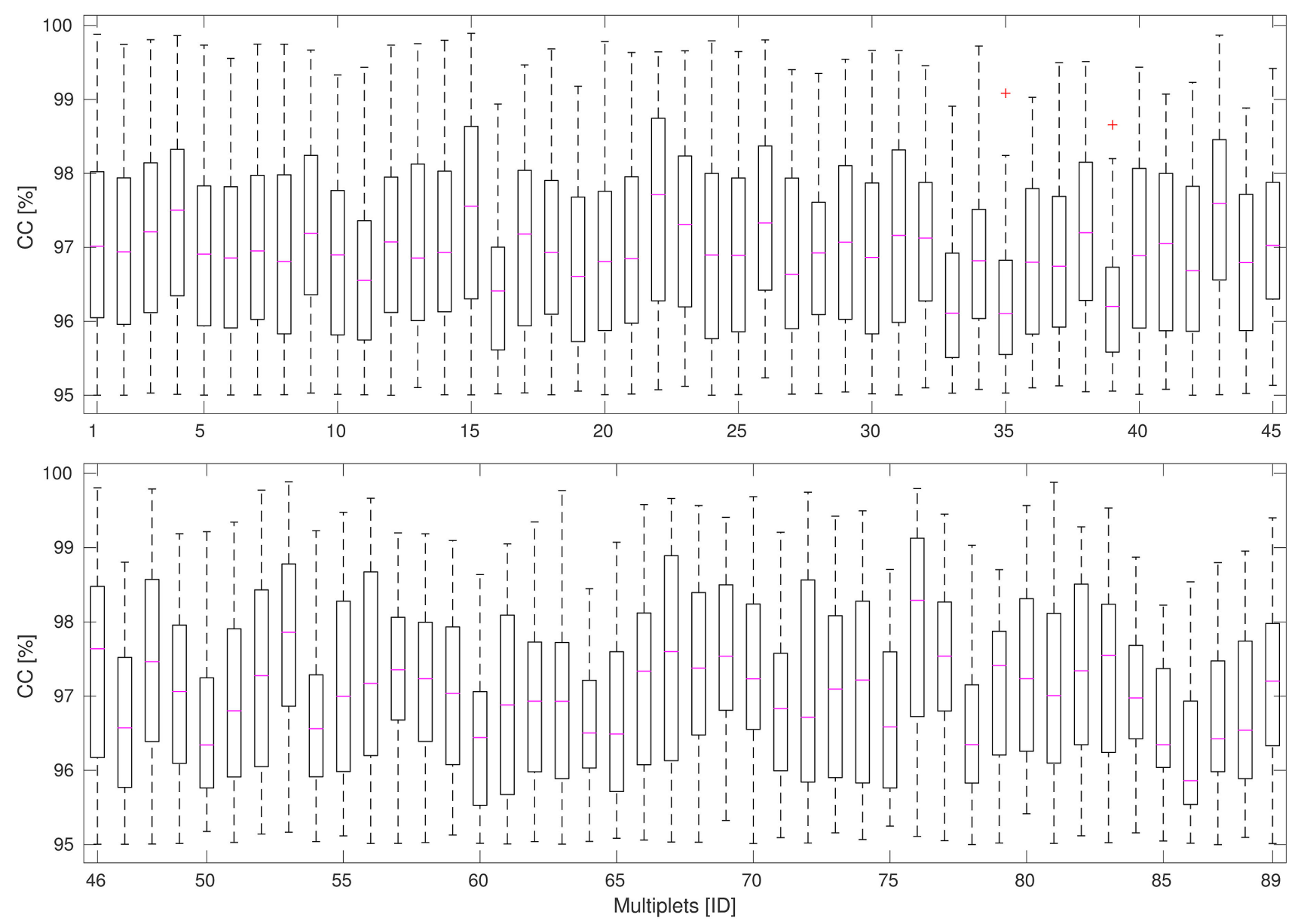

Figure 4. Boxplots of correlation coefficient (CC) in each multiplet with $N \geq 10$. Magenta lines show the median in each box, dashed lines show the most extreme data points which are not considered outliers, and outliers are plotted with '+' symbol.

Table 1. Differences in $X, Y$ and $Z$ directions between highly similar event pairs located using phase picked data only (PP) and phase picked data along with cross-correlated ones (CC \& PP).

\begin{tabular}{|c|c|c|c|c|c|c|}
\hline Differences (m) & \multicolumn{2}{|c|}{$X$} & \multicolumn{2}{|c|}{$Y$} & \multicolumn{2}{|c|}{$Z$} \\
\hline $0-150$ & 82 & 16 & 85 & 19 & 76 & 7 \\
\hline$>1000$ & 2 & 32 & 1 & 30 & 6 & 59 \\
\hline
\end{tabular}

probably artificially separated. An additional restriction is applied in this study for avoiding the 'chain effect' and/or false detections, namely, the doublet should be recorded by at least two stations. The highly similar event pairs are classified into 2150 multiplets of repeating events consisting of 8034 earthquakes which is more than the one-third ( 35 per cent) of the relocated catalogue.

The identified multiplets of repeating events vary in size with the vast majority (1320) classified as doublets. Triplets and quadruplets are also abundant whereas 89 multiplets include at least 10 events. The magnitude $\left(M_{\mathrm{L}}\right)$ range of repeating events is shorter than in the relocated catalogue (Fig. 3). Particularly, the earthquakes in the relocated catalogue have magnitudes from 0.1 to 5.0 , whereas the magnitudes $\left(M_{\mathrm{L}}\right)$ of repeating events are $0.2-3.4$. This shows that multiplets of repeating events contain small magnitude earthquakes. The high similarity between event pairs in each multiplet is illustrated in the boxplot of Fig. 4 where CC values of multiplets with $N \geq 10$ are drawn. Although the threshold value for CC was set to 95 per cent, the similarity of repeating events is significantly higher. This is clearly evidenced in each box where the event pairs in each multiplet have correlation coefficients between 96 and 98 per cent. There is no correlation between the number of stations in each multiplet and correlation coefficient.

\subsection{Mislocation}

Previous studies have shown that event pairs with very similar waveforms are co-located at a distance equal to a quarter of the dominant wavelength (Geller \& Mueller 1980; Schaff \& Richards 2004, 2011). Given a dominant frequency of $10 \mathrm{~Hz}$, which is the cut-off frequency used in this study, and assuming a velocity for $P$ waves equal to $6 \mathrm{~km} \mathrm{~s}^{-1}$, the dominant wavelength $(\lambda)$ is $600 \mathrm{~m}$. Considering the quarter wavelength rule, the differences between repeating earthquakes in $X, Y$ and $Z$ directions should be less than 

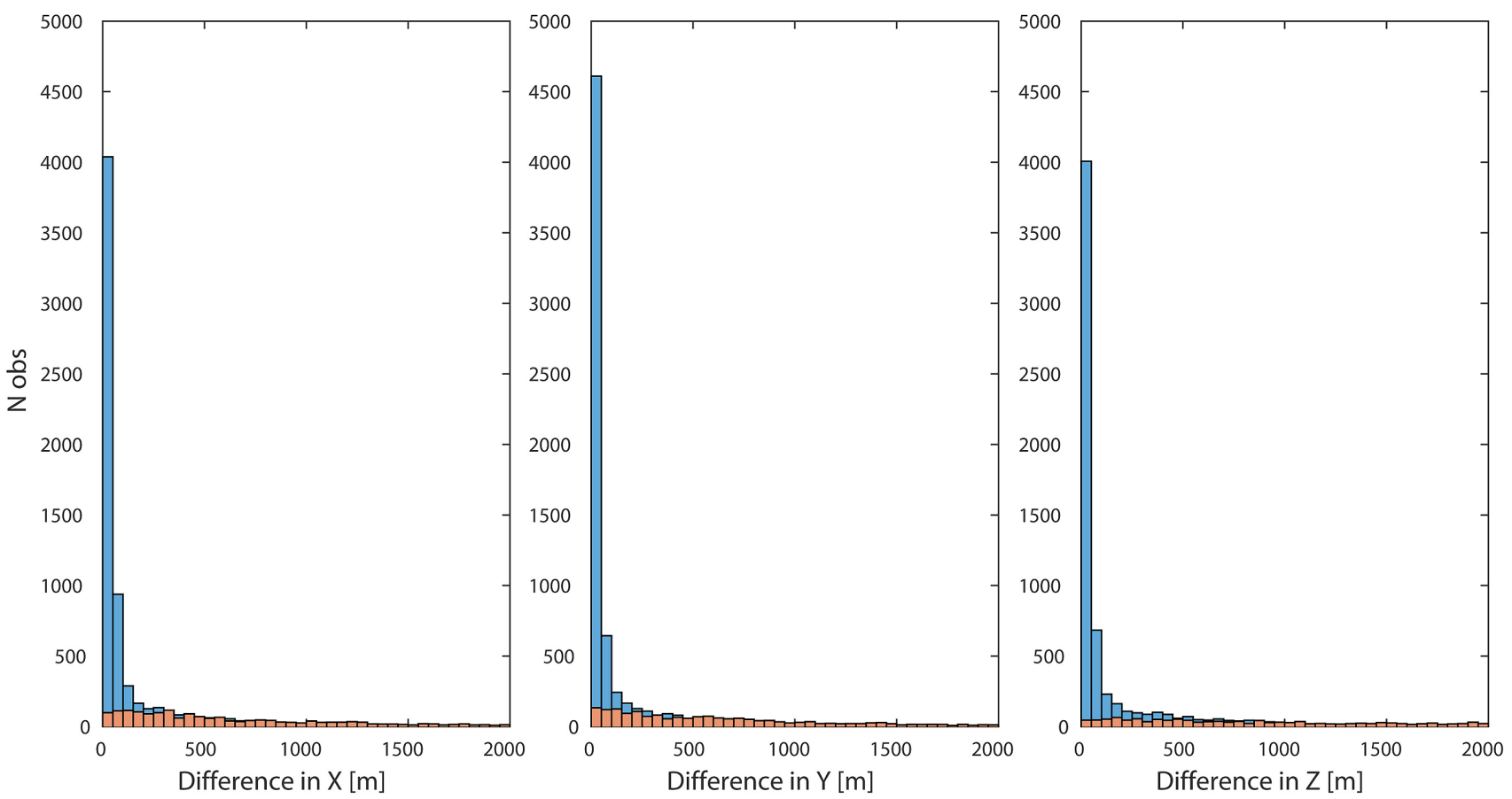

Figure 5. Histograms of differences in $X, Y$ and $Z$ directions for event pairs with $\mathrm{CC} \geq 95$ per cent located using both phase pick data and cross-correlation data (light blue) and located using only phase pick data (light brown).
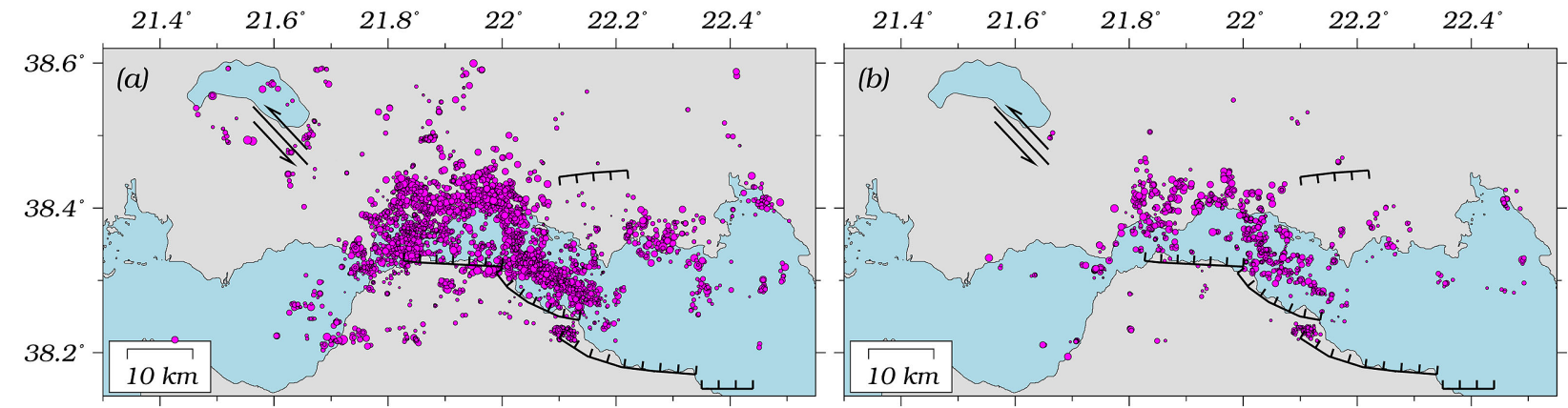

$-38.6^{\circ}$
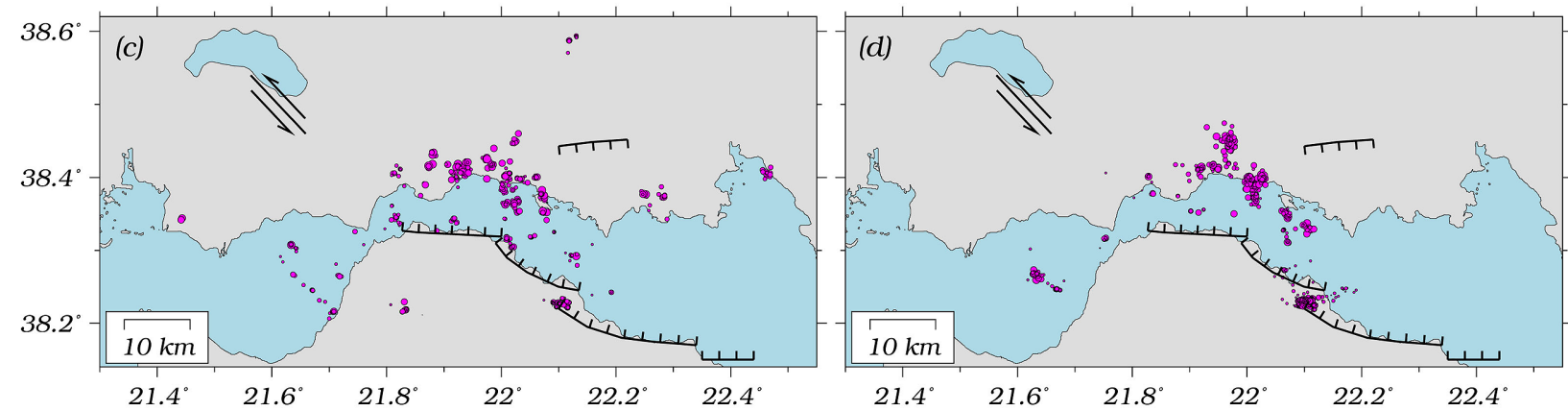

$38.6^{\circ}$

Figure 6. Spatial distribution of earthquakes which belong to multiplets of repeating earthquakes with (a) $2 \leq N<5$, (b) $5 \leq N<10$, (c) $10 \leq N<20$ and (d) $N \geq 20$ events.

$150 \mathrm{~m}$, which can be used to evaluate the accuracy of the relocated catalogue.

In this study, we used all the event pairs with $\mathrm{CC} \geq 95$ per cent and calculated the differences in $X, Y$ and $Z$ directions using the solutions of the relocated catalogue. These solutions were derived using both cross-correlated data and phase picked data or only phase pick data. In order to distinguish the two different types of data, we calculated separately the differences for event pairs that have at least one observation obtained from cross-correlation and for those that have only phase pick observations. The results are summarized in Table 1 and histograms for each direction are shown in Fig. 5 with each type of data denoted by different colour.

The median difference in the three directions $(X, Y$ and $Z)$ of the event pairs relocated using both cross-correlated and phase picked data is 33,22 and $31 \mathrm{~m}$, respectively. The vast majority of the differences in the three directions (76-82 per cent) are less than the 


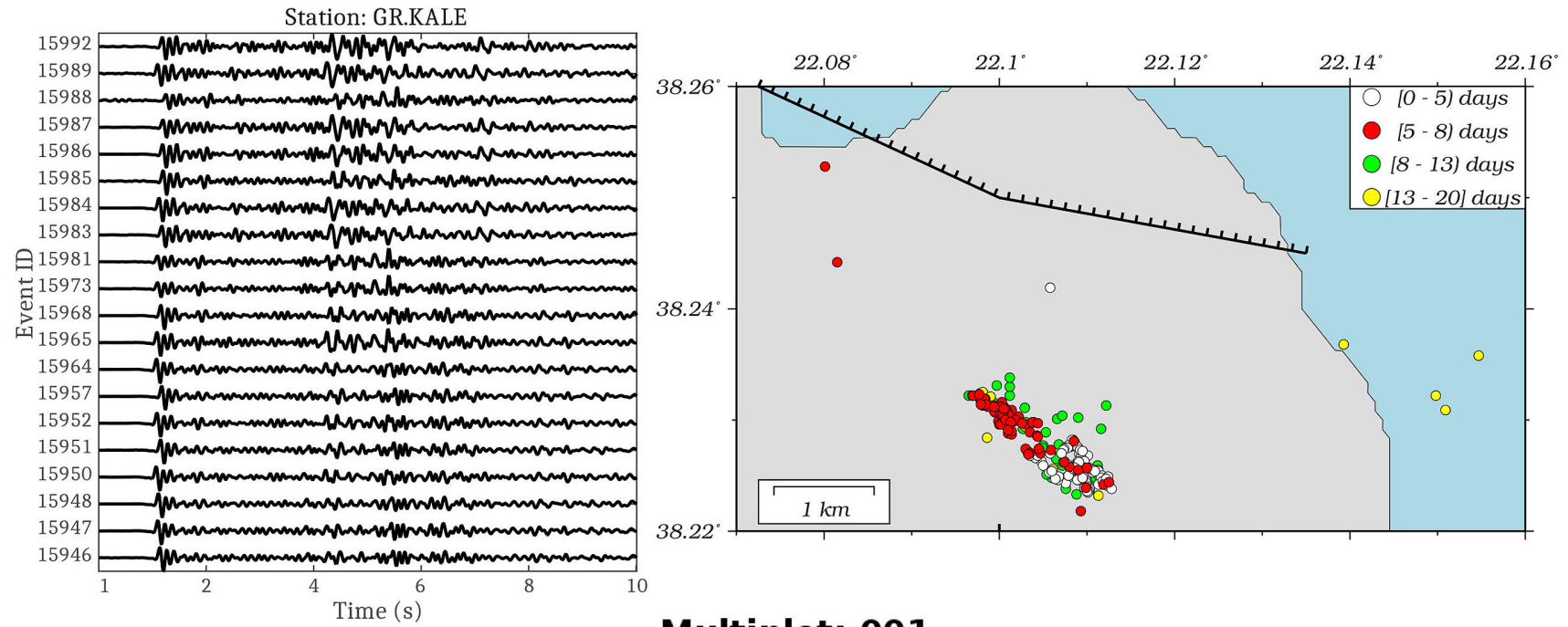

Multiplet: 001

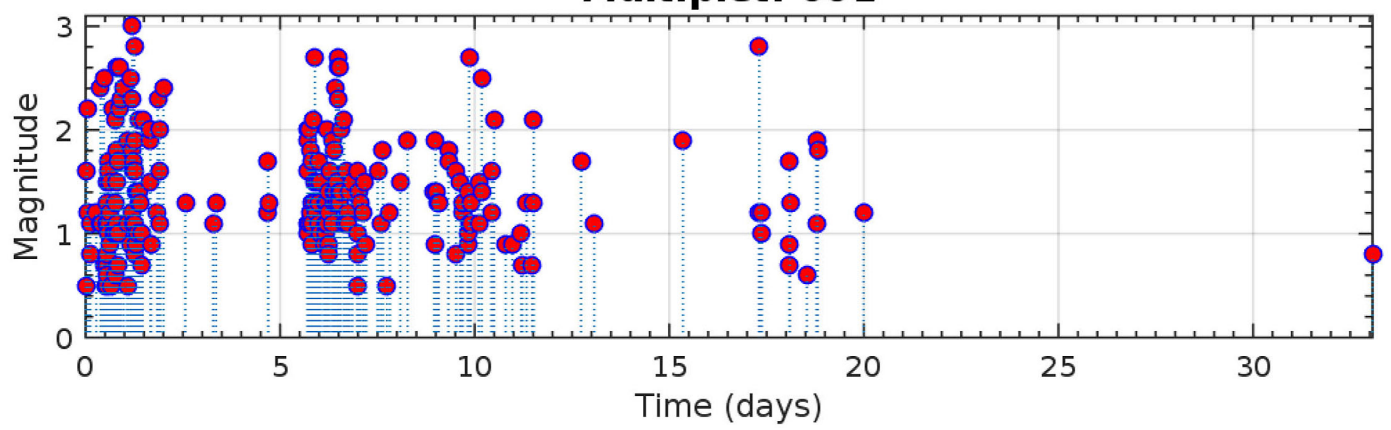

Figure 7. Example of a burst-like multiplet (ID = 001, Table A1 in the Appendix) with 229 events located in the area of the 2013 earthquake swarm. Upper panel: the spatial distribution of the events in the multiplet is shown on the map along with the similarity of the waveforms of few selected events recorded at station KALE. Lower panel: magnitude distribution with time, zero time corresponds to 2013 May 21, 13:28:53.18.

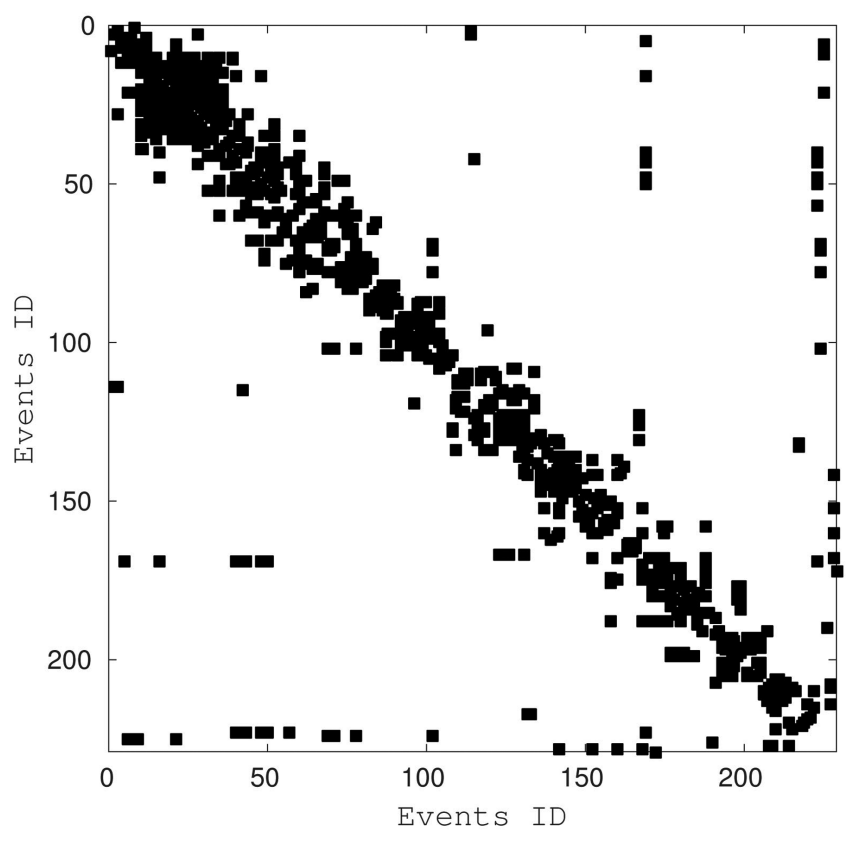

Figure 8. Doublet matrix of multiplet 01 with event pairs sorted by distance from the northwestern tip of the multiplet. Squares indicate each doublet satisfying the criteria set in this study. length of the quarter wavelength rule $(150 \mathrm{~m})$, evidencing the high accuracy of the relocated catalogue, when the events are located using both cross-correlation and phase picked data. On the other hand, relocations obtained using only phase picked data have larger median values, namely, 553, 573 and $1300 \mathrm{~m}$ and a small portion of the event pairs (7-16 per cent) have differences less than $150 \mathrm{~m}$. The aforementioned differences in the location between event pairs are comparable with location errors of the relocated catalogue, which have been estimated using a bootstrap method and are of the order of few hundred metres (Mesimeri et al. 2018).

\subsection{Spatio-temporal properties}

The earthquakes which are members of multiplets of repeating events are distributed in the entire western Corinth Gulf with most of them located between $21.7^{\circ}$ and $22.2^{\circ}$ (Fig. 6). However, if we break down the number of events in a multiplet, we observe a pattern between the number of events in a multiplet and the spatial distribution. Particularly, for the multiplets with less than 5 or 10 events (Figs 6a and b) the earthquakes are distributed in the entire study area. When we isolate multiplets with events between 10 and 20 (Fig. 6c), as well as those with at least 20 events (Fig. 6d), the earthquakes are concentrated mostly in two areas, namely, on the northern coasts of western Corinth Gulf and in the area of 2013 earthquake swarm.

Multiplets with $N \geq 10$ can be further distinguished regarding their duration into burst-like repeaters (45), lasting from few hours to 

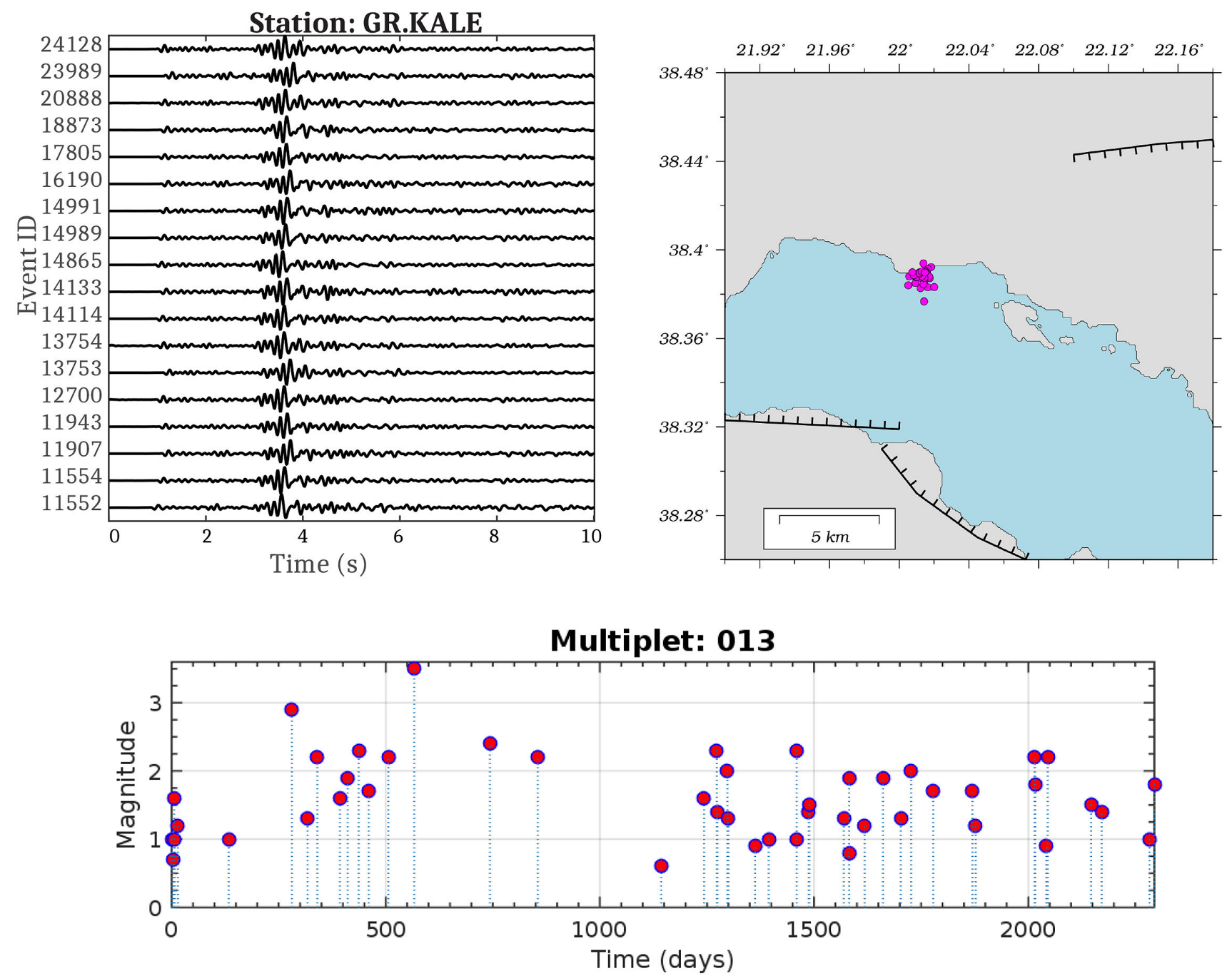

Figure 9. Same as Fig. 6 for a continuous-type multiplet (ID $=013$, Table A1 in the Appendix) with 48 events located on the northern part of the rift. Zero time corresponds to 2008 September 3, 13:53:39.88.

a year and continuous-type repeaters (39) that last almost the entire study period (4-7 yr). There are only five multiplets of repeating events that last from 1 to $4 \mathrm{yr}$ which are considered as repeaters of continuous type. The aforementioned spatial pattern matches the temporal distinction with most of the burst-like repeaters located onshore in the area of 2013 Aigion swarm (Kapetanidis et al. 2015; Mesimeri et al. 2016; Kaviris et al. 2017) at the southern part of the rift whereas the continuous-type repeaters are located both offshore and beneath the northern coasts of the rift.

Two characteristic examples of burst-like and continuous-type repeaters are shown in Figs 7 and 9, respectively. The multiplet with the largest size (229 events, Table A1 in the Appendix) is characterized as burst-like repeater and located in the area of the 2013 Aigion swarm (map in Fig. 7). The repeating events have very similar waveforms, as shown in the upper-left panel of Fig. 7, where a few of the repeating events of multiplet 01 recorded at station KALE are plotted. The spatial distribution of the repeating earthquakes expands to a total length of $2 \mathrm{~km}$. A detailed examination of the temporal evolution reveals two major phases. During the first 5 $\mathrm{d}$ the activity is concentrated on the southeastern part of the cluster (white circles, Fig. 7), then migrated to the northwestern part (red circles, Fig. 7) and finally spread in the entire area and ceased with time (green and yellow circles, Fig. 7). Due to the length of the rupture area $(2 \mathrm{~km})$, the similarities of all the repeating events defined here, using the aforementioned criteria, are checked in terms of the correlation coefficient values. The earthquakes were sorted according to their distance from the northwestern tip of the sequence. Each of the axes of Fig. 8 shows the order index of the events as in Schaff $\&$ Richards (2011). The event pairs satisfying the criteria of doublets in two or more stations are shown with a solid black square. The closer the distance from the diagonal, the smaller the difference in the order index. However, because the cluster is elongated in a narrow NW-SE oriented zone, this matrix is a measure of the spatial differences of the event pairs. From the width of the black band along the diagonal, it is derived that the difference in location between highly similar event pairs is less than $100 \mathrm{~m}$. There are only a few exceptions that show large deviations from the diagonal in the matrix which most probably concern mislocated events located using only phase picked data (see Section 3.2).

An example of continuous-type repeater is shown in Fig. 9 which corresponds to multiplet 13 (Table A1 in the Appendix). The multiplet is located beneath the northern coast of the study area and is extended up to a length of $1.1 \mathrm{~km}$. The duration of this multiplet is almost $7 \mathrm{yr}$, which is the entire study period (lower panel). This 

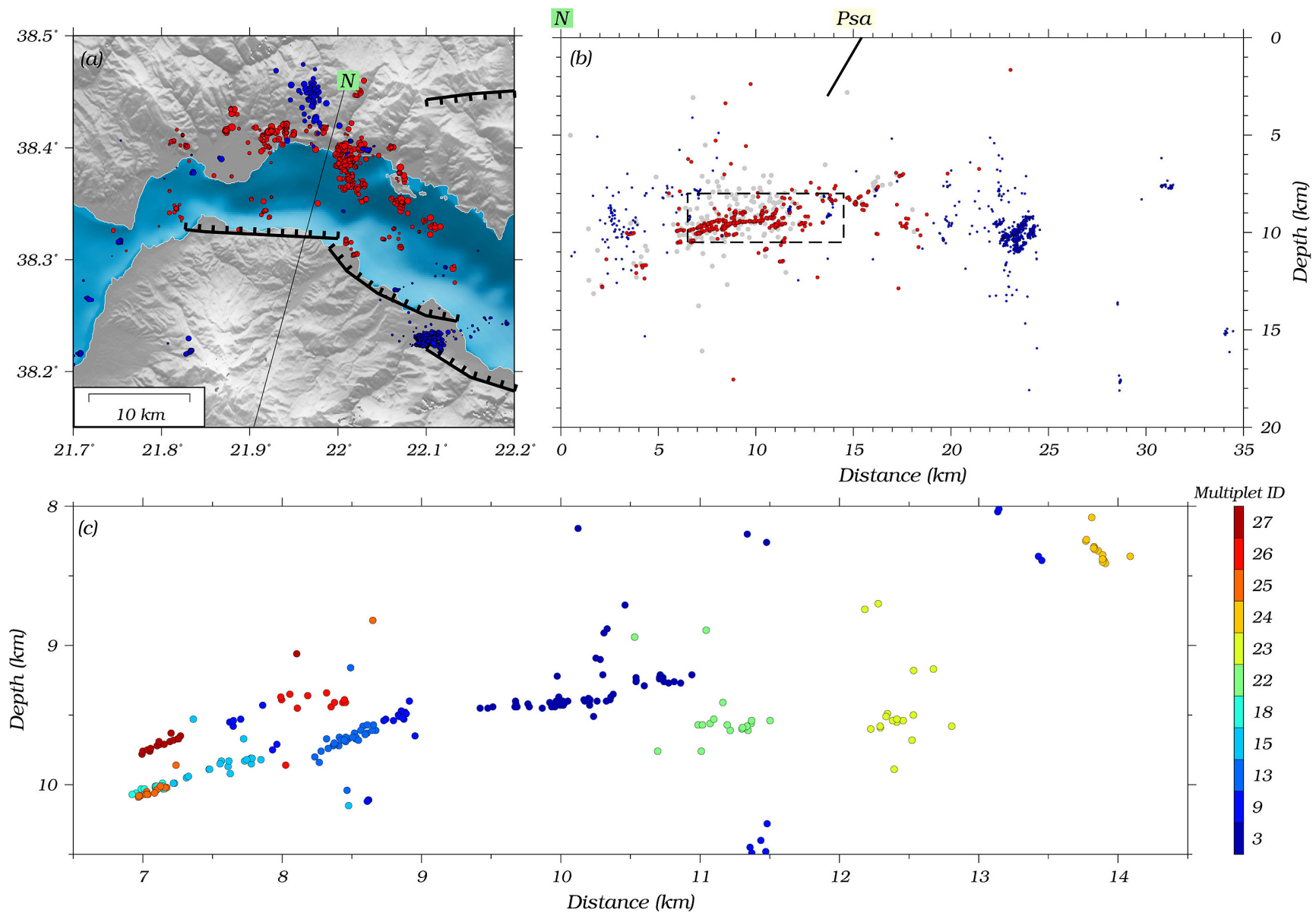

Figure 10. (a) Epicentral distribution of burst-like repeaters (blue circles) and continuous-type repeaters (red circles). (b) Cross-section normal to the mean trend of the rift. The different types of repeaters are denoted by different colours, whereas events that occurred before 2011 are depicted with grey circles. (c) Zoom-in to the data surrounded by the rectangle in Fig. 8(b), where the earthquakes that belong to repeating sequences with $N \geq 20$ are shown by different colours based on their ID number.

continuous activity is manifested mainly by low magnitude events $\left(1<M_{\mathrm{L}}<2\right)$ and only one event with $M_{\mathrm{L}}>3$. The waveforms of events recorded at station KALE are shown on the upper-left panel of Fig. 9.

The epicentres of burst-like repeaters (duration $<1 \mathrm{yr}$ ) along with the continuous-type repeaters (duration $\geq 1 \mathrm{yr}$ ) with $N \geq 10$ are shown in Fig. 10(a) with blue and red circles, respectively. The spatial distribution reveals that the two groups are located in different areas and most probably these are the results of different triggering mechanism. A normal to the mean strike of the rift cross-section (Fig. 10b) is constructed in order to compare the foci distribution of the two types of repeaters. The burst-like repeaters are mostly related to the 2013 Aigion swarm and in a few cases are widespread across the rift. On the other hand, the continuoustype repeaters form a very narrow shallow dipping seismic zone located north of the Psathopyrgos and Aigion faults, which was also observed in Mesimeri et al. (2018) by the relocated microseismicity. In Fig. 10(c), which is a zoom-in to the data surrounded by the rectangle in Fig. 10(b), 10 repeating events of continuous type are plotted by different colours in a cross-section similar to Fig. 10(b). It is illustrated that the different multiplets of repeating events are comprised in different patches of the seismic zone, activated repeatedly during the study period. An important feature of this activity is the small rupture areas which do not exceed $2 \mathrm{~km}$.
Regarding the triggering mechanism, we searched for any possible relation between fluid intrusion and the occurrence of repeating events. In this respect, we created distance-time plots ( $r-t$ plots) and looked for a triggering front as well as a back front, which are considered as signatures of fluid-induced seismicity (Shapiro 2015). Initially, we examined two earthquake clusters occurred in western Corinth Gulf (appendix B in Mesimeri et al. 2018) identified using CURATE algorithm (Jacobs et al. 2013). These two clusters consist of several burst-like repeaters, which are identified in this study, with variable sizes. The $r-t$ plots (Figs 11a and b) evidence that the two seismic excitations can be described by the two fronts (triggering and back) with different values of diffusivity (D). Particularly, Fig. 11(a), which corresponds to the cluster W05, has D $=1.3 \mathrm{~m}^{2}$ $\mathrm{s}^{-1}$ for the triggering front and $\mathrm{D}=0.3 \mathrm{~m}^{2} \mathrm{~s}^{-1}$ for the back front and includes 30 burst-like repeaters (colour bar in Fig. 11a). These repeaters ruptured very small patches and are triggered, most probably, by fluid diffusion. Their mechanism is different due to changes in pore pressure resulting to several multiplets of repeating events. A similar pattern is observed in Fig. 11(b), where the $r-t$ plot of the W32 cluster is plotted along with 12 burst-like repeaters. The value of the diffusivity for the triggering front is $\mathrm{D}=0.5 \mathrm{~m}^{2} \mathrm{~s}^{-1}$ and for the back front $\mathrm{D}=0.2 \mathrm{~m}^{2} \mathrm{~s}^{-1}$.

The $r-t$ plots for continuous-type repeaters, which are not clustered spatio-temporally, showed the rupture of the same patch throughout the study period (Figs 11c and d). In Fig. 11(c), the 

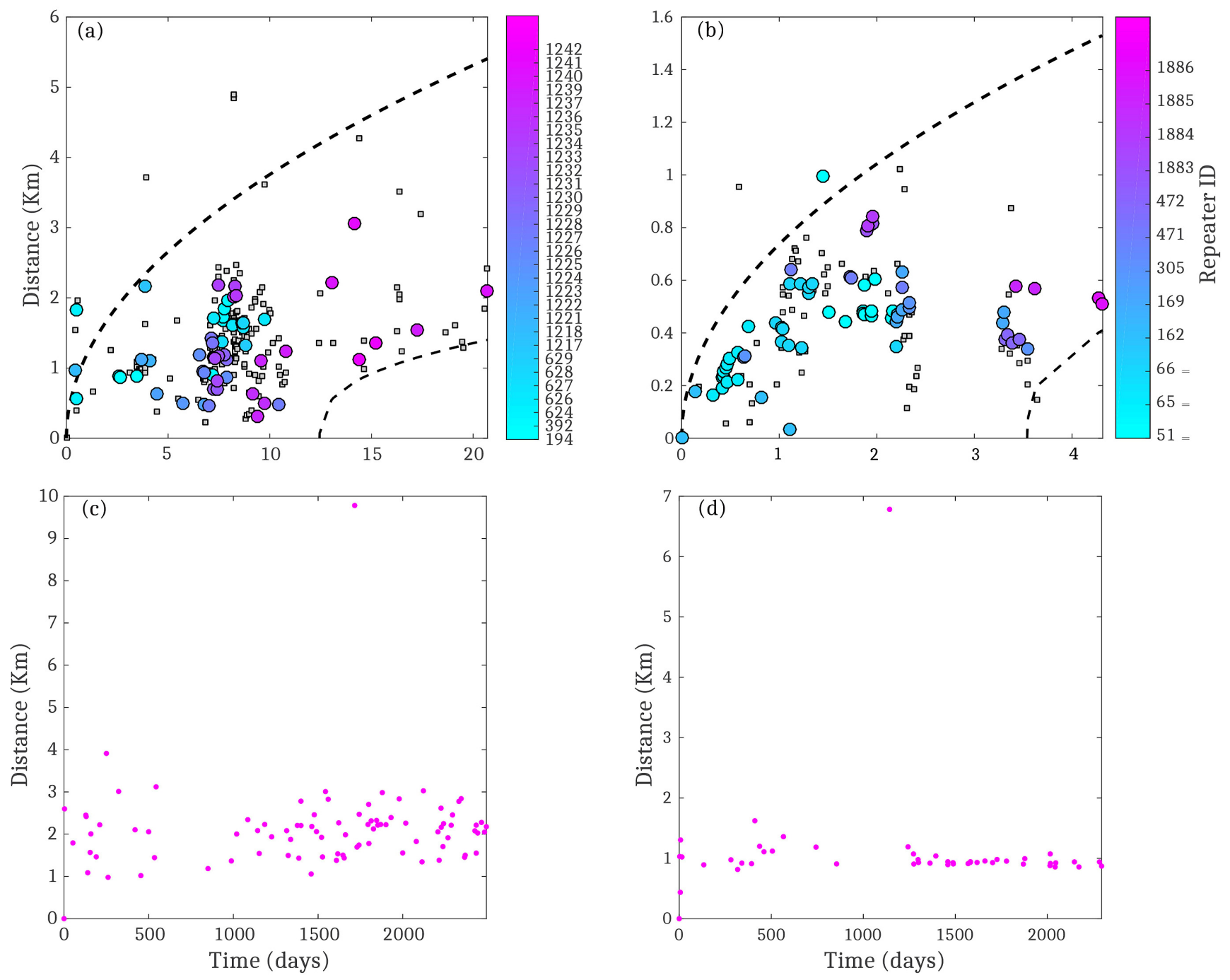

Figure 11. (a and b) $r-t$ plots for clusters W05 and W32 (appendix B in Mesimeri et al. 2018) along with burst-like repeaters identified in this study and plotted with different colours. Focal parameters and origin time for zero point are $21.8397^{\circ} \mathrm{E}, 38.4265^{\circ} \mathrm{N}, 9.73 \mathrm{~km}, 2010 \mathrm{May} 06,10: 08: 17.03$ for cluster W05 and $22.0299^{\circ} \mathrm{E}, 38.3990^{\circ} \mathrm{N}, 7.84 \mathrm{~km}, 2013$ September $09,16: 26: 48.21$ for cluster W32. (c and d) $r-t$ plots for two multiplets of continuous type (03, 13, Table A1 in the Appendix). Focal parameters and origin time for zero point are $220.210^{\circ} \mathrm{E}, 38.3598^{\circ} \mathrm{N}, 8.19 \mathrm{~km}, 2008$ February $28,03: 16: 56.97$ for multiplet 03 and $22.0183^{\circ} \mathrm{E}, 38.3923^{\circ} \mathrm{N}, 8.95 \mathrm{~km}, 2008$ September $03,13: 53: 39.88$ for multiplet 13.

largest in size multiplet (03, Table A1 in the Appendix) is plotted, for which an area less than $2 \mathrm{~km}$ is occupied. There is no evidence for triggering front, instead the earthquakes are originated at the same patch. Similarly, in Fig. 11(d), the $r-t$ plot of multiplet 13 (Table A1 in the Appendix) shows a smaller patch, less than $1 \mathrm{~km}$, which is activated during the entire study period. These two characteristic examples provide strong evidence for the triggering mechanism in the shallow north-dipping zone, which is most probably due to tectonic loading.

\section{ESTIMATION OF SLIP RATES}

Repeating events as repeated slips of the same small asperities can be used to estimate the amount of aseismic slip in an area (e.g. Nadeau \& Johnson 1998; Igarashi et al. 2003; Templeton et al. 2008). In respect to that, we calculated the slip rate for each multiplet. Initially, we assume that $M_{\mathrm{L}}$ magnitudes are equivalent to moment magnitudes $\left(M_{\mathrm{w}}\right.$; Scordilis et al. 2016) and can be converted to scalar moment $\left(M_{\mathrm{o}}\right)$ using the relationship of Hanks \&
Kanamori (1979; in SI units)

$M_{\mathrm{o}}=10^{\left(1.5 M_{\mathrm{L}}+9.1\right)}$.

Then, we calculated the cumulative moment ( $\Sigma M$ ) by summing up the moments of all events and use the sum to estimate the average slip

$\Sigma M_{\mathrm{o}}=\mu A D$,

where $\mu$ is the shear modulus, taken equal to $33 \mathrm{GPa}$, and $A$ is the fault area

$A=\pi r^{2}$

assuming a circular crack model (radius, $r$ in metres)

$r=\left(\frac{7 \Sigma M_{\mathrm{o}}}{17 \Delta \sigma}\right)^{\frac{1}{3}}$

and a constant stress drop $\Delta \sigma$ equal to $3 \mathrm{MPa}$ (Keilis-Borok 1959). Finally, the slip rates for each multiplet are calculated by dividing the average slip with its duration in years. 


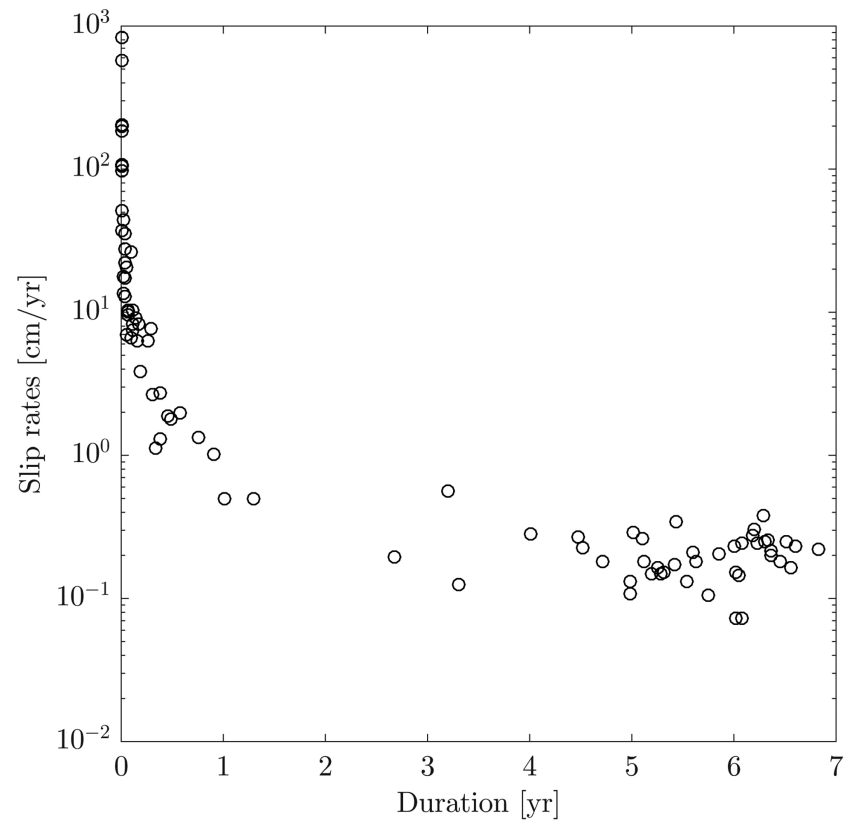

Figure 12. Slip rates against duration for the multiplets with more than 10 events.

The estimated slip rates for multiplets with $N \geq 10$ vary by several orders of magnitude (Table A1 in the Appendix). A strong correlation between duration and slip rates is shown in Fig. 12. A time threshold seems to hold close to $1 \mathrm{yr}$, which is in agreement with the classification made before. In more detail, the multiplets with long duration ( $\geq 1 \mathrm{yr}$ ) have slip rates in the range of $0.07-$ $0.56 \mathrm{~cm} \mathrm{yr}^{-1}$, with a mean value of $0.22 \mathrm{~cm} \mathrm{yr}^{-1}$ and a median of $0.20 \mathrm{~cm} \mathrm{yr}^{-1}$. Additionally, we calculated the slip rates for the earthquakes that occurred since 2011 and belong to continuoustype repeaters, taking into consideration the gradual increase of the network coverage, which improves the earthquake detectability. The calculated slip rates are slightly larger and ranging between 0.15 and $0.4 \mathrm{~cm} \mathrm{yr}^{-1}$, with a mean value of $0.26 \mathrm{~cm} \mathrm{yr}^{-1}$. On the other hand, the mean slip of multiplets with short duration $(<1 \mathrm{yr})$ is $0.86 \mathrm{~cm}$ with a median of $0.76 \mathrm{~cm}$. The estimated mean annual slip rate, considering that the activity persists for the entire year, is $67.10 \mathrm{~cm} \mathrm{yr}^{-1}$ with a median equal to $10.43 \mathrm{~cm} \mathrm{yr}^{-1}$, which has no physical meaning and expresses the short duration of burst-like repeaters. Thus, burst-like activity is the result of the accumulated for long time strain or the result of triggering of other sources such as fluid diffusion or static or dynamic stress transfer.

The spatial distribution of slip rates for multiplets with at least 10 events according to their duration is shown in Fig. 13. The burst-like repeaters lasting up to $1 \mathrm{yr}$ are shown in Fig. 13(a), with different colours based on the values of slip rate. We observe a large concentration of multiplets with high slip rates $(>>1 \mathrm{~cm}$ $\mathrm{yr}^{-1}$ ) in the area of the 2013 Aigion swarm. Burst-like repeaters require slip rates which cannot be explained by tectonic loading, evidencing a possible relation to fluid-driven seismicity. On the other hand, the continuous-type repeaters, which last more than 1 yr, have low values of slip rate (Fig. 13b) and are located offshore and beneath the northern coasts of the rift. The vast majority of multiplets with low slip rates are placed in the area between the two major faults (Psathopyrgos and Aigion) and their values indicate a possible relation to the tectonic loading in the area.

\section{RECURRENCE INTERVALS}

The recurrence intervals between subsequent events in a multiplet are quantified using the coefficient of variation (COV):

$\mathrm{COV}=\frac{\sqrt{\frac{\sum_{i=1}^{N}\left(T \mathrm{r}_{i}-\overline{T \mathrm{r}}\right)^{2}}{N}}}{\overline{T \mathrm{r}}}$,

where $T$ ris the recurrence interval between consecutive events in a multiplet, $\overline{T r}$ is the mean recurrence for each multiplet and $N$ is the number of recurrence intervals in a multiplet. COV values smaller than 1 indicate either perfect periodicity $(\mathrm{COV}=0)$ or quasiperiodicity $(\mathrm{COV}=0.5)$, $\mathrm{COV}$ values equal to 1 denote a Poisson occurrence, whereas COV larger than 1 show temporal clustering (Kagan \& Jackson 1991). The results are shown in the histogram of Fig. 14 where only multiplets with $N \geq 3$ are considered (COV $=0$ for doublets). The multiplets have a wide range of COV values and they form groups that fall into the aforementioned categories. Particularly, 44 per cent of the multiplets indicate a periodic to quasi-periodic occurrence [0-0.8], 34 per cent have values near 1 [0.8-1.2] denoting a Poisson occurrence and 22 per cent obtain values greater than 1 [1.2-6.4] showing temporal clustering.

$\mathrm{COV}$ values are plotted against the duration of each multiplet and the estimated slip rates (Fig. 15) in an attempt to identify possible patterns. When we plot the multiplets with $N \geq 10$ and $N \geq 20$, we observe a tendency of clustering in two main groups (Fig. 15, upper panel). COV values close to 1 are mostly located at the bottom right of the plot (duration longer than $1 \mathrm{yr}$ ) whereas multiplets with COV $>1$ have short duration (Fig. 15). A similar pattern is observed when we plot the estimated slip rates against COV values (Fig. 15, lower panel). $\mathrm{t}$ is clear that multiplets with low slip rates $\left(<0.5 \mathrm{~cm} \mathrm{yr}^{-1}\right)$ have COV values close to one, whereas multiplets with $\mathrm{COV}>1$ have high slip rates $\left(>>0.5 \mathrm{~cm} \mathrm{yr}^{-1}\right)$. Combining the above, we suggest that repeaters with $\mathrm{COV} \sim 1$ and low slip rates $\left(<0.5 \mathrm{~cm} \mathrm{yr}^{-1}\right)$ are caused mainly due to tectonic loading. These repeaters are of continuous type, last almost the entire study period and are located offshore and beneath the northern coasts of the rift. The scattering observed in larger values of COV and slip rates concerns the burst-like repeaters, which have short durations. These multiplets are triggered by different mechanisms such as fluid intrusion or static or dynamic stress transfer.

For the doublets we followed the approach of Schaff \& Richards (2011) and plot the recurrence time of each doublet against the mean magnitude (Fig. 16) along with theoretical recurrence times if we assume a constant tectonic loading $\left(0.1-3 \mathrm{~cm} \mathrm{yr}^{-1}\right)$. The doublets are grouped into two main categories according to their slip rates. Doublets with estimated slip rates less than $0.5 \mathrm{~cm} \mathrm{yr}^{-1}$ (Fig. 16, blue circles) and those with slip rates $>>0.5 \mathrm{~cm} \mathrm{yr}^{-1}$ (Fig. 16, brown circles). This result indicates that if tectonic loading was responsible for the occurrence of doublets with high slip rates, then the slip rate would be larger than $3 \mathrm{~cm} \mathrm{yr}^{-1}$. On the other hand, doublets with low slip rates require tectonic loading equal to less than $0.5 \mathrm{~cm} \mathrm{yr}^{-1}$.

\section{DISCUSSION}

In this study, we identified 2150 multiplets of repeating events in the western Corinth Gulf during 2008-2014, recorded by at least two stations and present similar seismograms. The highly similar event pairs revealed that the accuracy of the relocated earthquake catalogue is of the order of tens of metres. Furthermore, after examining the spatio-temporal evolution of each repeating sequence 

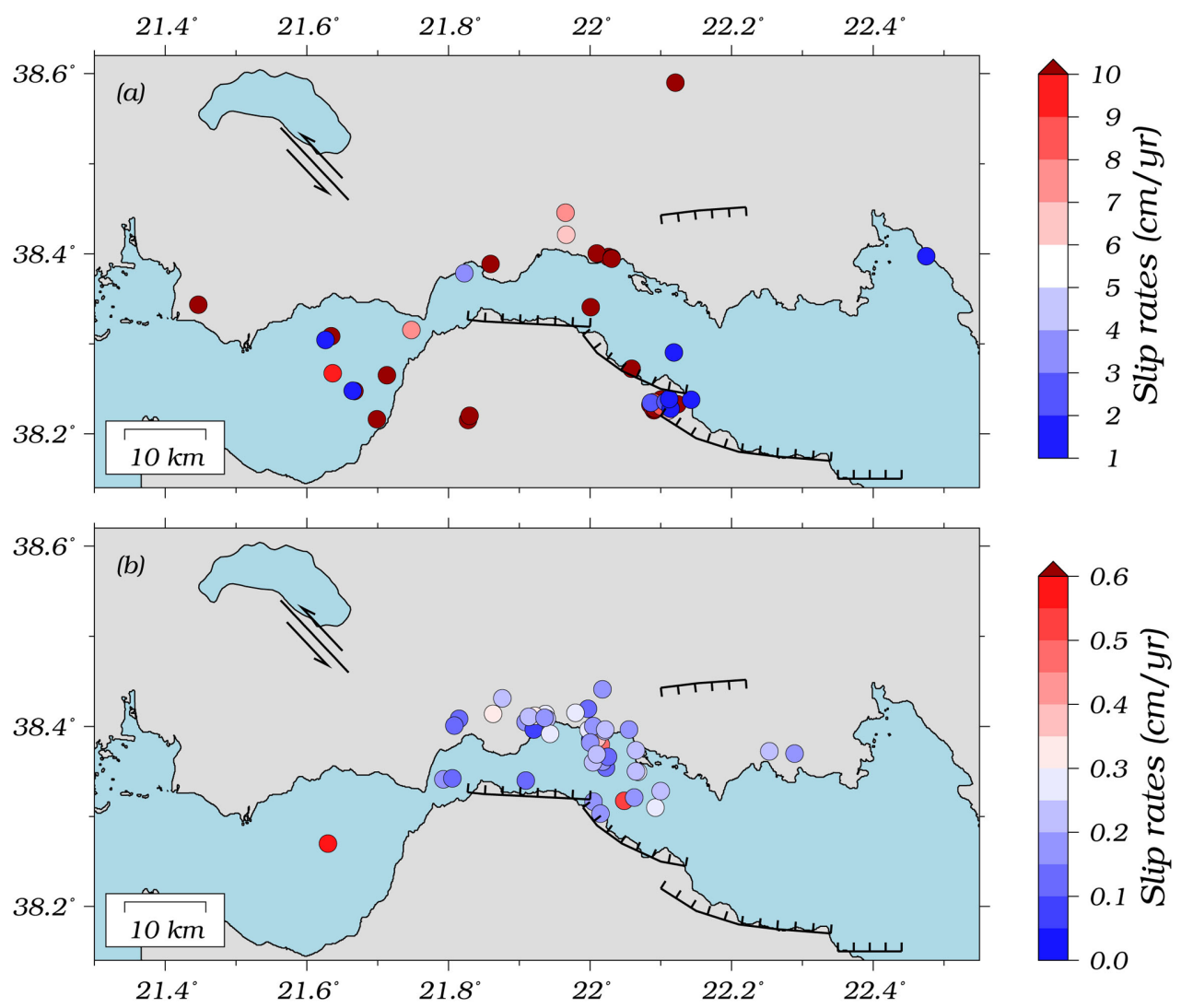

Figure 13. Spatial distribution of slip rates $\left(\mathrm{cm} \mathrm{yr}^{-1}\right)$ for the multiplets with more than 10 events and duration (a) less than $1 \mathrm{yr}$ and (b) more than $1 \mathrm{yr}$.

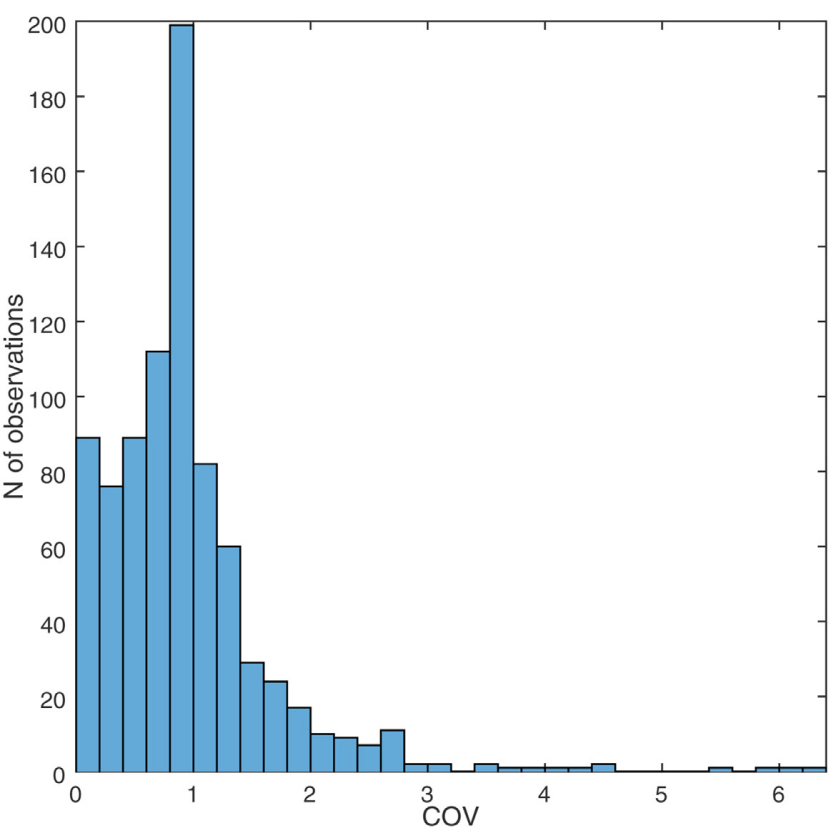

Figure 14. Histogram of COV values for the 830 multiplets with $N \geq 3$.

we identified two types of repeaters. Particularly, multiplets of repeating events that have short interevent times and last few hours to few days (burst-like repeaters) and multiplets that last almost the entire study period (continuous-type repeaters).

Burst-like repeaters are widespread in the entire study area and associated with earthquake excitations that occurred on small fault segments dipping with high angles $\left(45^{\circ}-60^{\circ}\right.$; Mesimeri et al. 2018$)$. A characteristic example is the 2013 Aigion earthquake swarm, which consists of several multiplets of repeating events. Additionally, burst-like repeaters have very high slip rates $(>>1 \mathrm{~cm}$ $\mathrm{yr}^{-1}$ ) which cannot be interpreted by the regional tectonic loading alone, and indicate a different triggering mechanism, most probably related to the existence of fluids. Another implication of triggering is the very high COV, which shows temporal clustering. The high slip rates along with the short duration of the multiplets evidence the strong influence of fluids in earthquake generation.

On the other hand, continuous-type repeaters form a very narrow shallow north-dipping zone offshore and beneath the northern coast of western Corinth Gulf, particularly north of Psathopyrgos and Aigion fault traces. Their duration, which in most cases spans the entire study period, differs significantly from the burstlike repeaters. After estimating the slip rates of continuous-type repeaters, we found an average value of slip rate equal to $0.26 \mathrm{~cm}$ $\mathrm{yr}^{-1}$. Regarding the COV values, we found that continuoustype repeaters have COV close to one, which indicates Poisson occurrence.

Similar streaks of microearthquakes have been found in known creeping faults (e.g. Rubin et al. 1999; Waldhauser \& Ellsworth 2002) and are interpreted as the boundary of the seismogenic zone where the locked part of the faults lay above them. Another example is the case of Alto Tiberina fault, where microseismicity defines a low-angle normal fault (Chiaraluce et al. 2007; Valoroso et al. 2017), lower parts of which are creeping aseismically whereas the shallow locked portions are compatible with an $M>6.5$ earthquake (Anderlini et al. 2016). In the case of western Corinth Gulf, the shallow north-dipping zone was interpreted as a detachment zone 

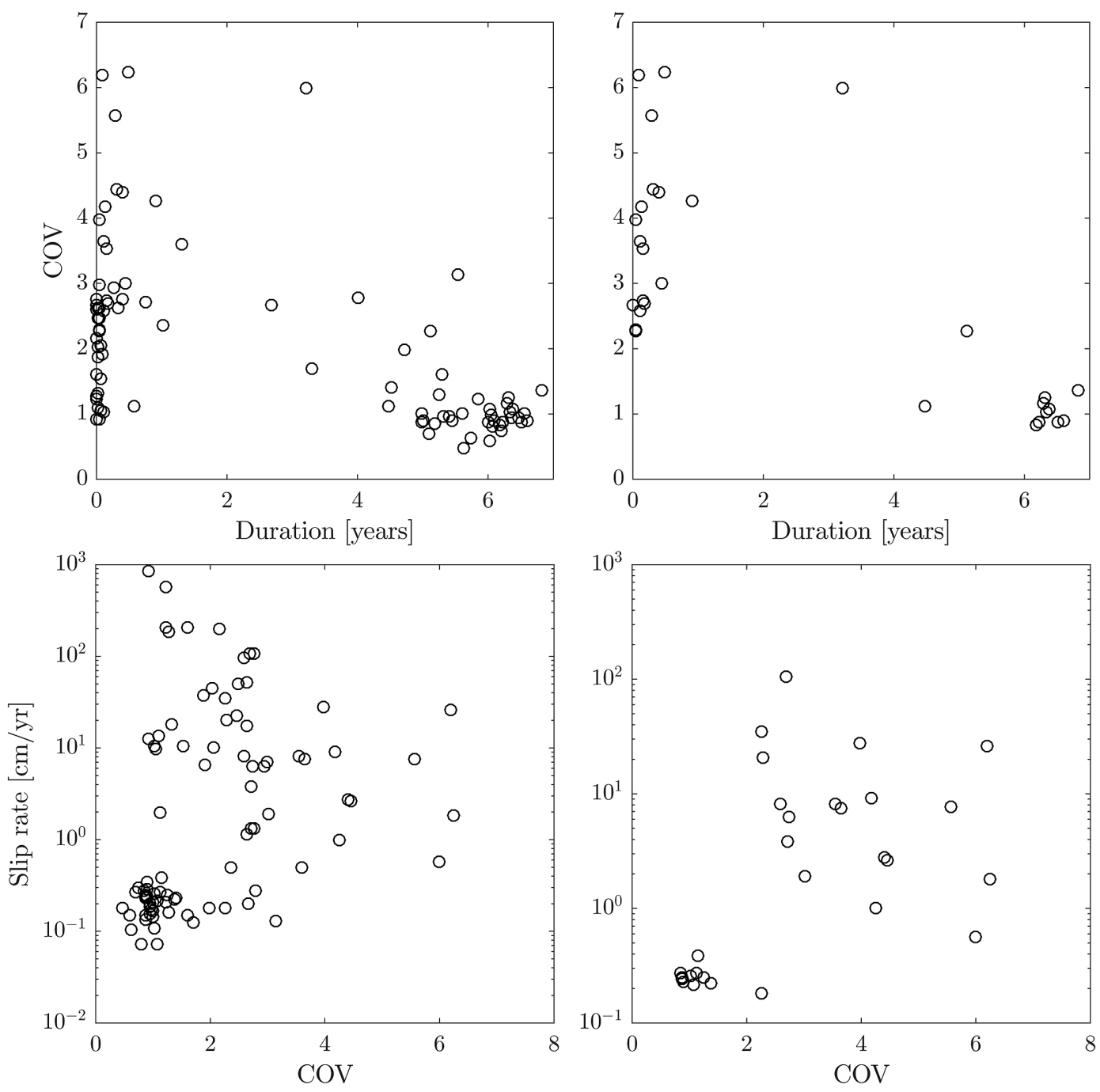

Figure 15. COV against duration (upper panel) and slip rates against COV (lower panel) for the multiplets with more than 10 and 20 events, respectively.

where the north-dipping faults are rooting (Rigo et al. 1996; LyonCaen et al. 2004; Bernard et al. 2006; Lambotte et al. 2014) or associated with the brittle-ductile transition (Hatzfeld et al. 2000; Mesimeri et al. 2018). A mechanical interpretation assumes that microseismic activity, in western Corinth Gulf, is caused due to the formation of Riedel-type shear bands within thick fault zone and corresponds to low magnitude earthquakes $2.7 \leq M \leq 4.7$ (Lecomte et al. 2012). Dublanchet et al. (2015) studied a multiplet of earthquakes with similar waveforms that lasted $7 \mathrm{yr}$ and located on the edge of the Aigion fault. They concluded that this multiplet could hardly be interpreted as a set of asperities surrounded by a locked fault enviroment.

In this work, the association of the shallow seismic zone with a detachment or with the transition from the brittle to ductile layer is investigated in the sense of Coulomb stress transfer. In the case of the detachment, Coulomb stress is transferred to the above located main faults Psathopyrgos and Aigion. In the case of creeping between the brittle and ductile layers, no stress is transferred. For the calculation of the stress transfer, the model of the virtual negative displacement as it was introduced by Deng \& Sykes (1997) was applied using the DIS3D program (Erickson 1986). The small magnitude earthquakes of continuous-type repeaters, with rather regular interevent times, are considered to occur in small asperities embedded in a region which is creeping stably. Thus, the slip rate calculated for these small patches represents the sliding in the surrounding area.

Particularly, we consider that the shallow north-dipping zone can be distinguished into two planes (boxes in Fig. 17a) striking $270^{\circ}$ and $300^{\circ}$, respectively, occupying the offshore area, where it has been found that the accumulated strain is released (Briole et al. 2000). For the first plane, which is beneath the Psathopyrgos fault, we account a length of $17 \mathrm{~km}$, a width of $12 \mathrm{~km}$ and a dipping angle equal to $15^{\circ}$. The strike of Psathopyrgos fault is $270^{\circ}$ with a dipping angle of $40^{\circ}$, and length and width equal to 16 and 8 $\mathrm{km}$, respectively. As for the second plane, located beneath Aigion fault, we considered a dipping angle of $15^{\circ}$, a length of $15 \mathrm{~km}$ and a width of $9 \mathrm{~km}$. The geometry of the Aigion fault was based on the fault plane solution of the 1995 earthquake (Bernard et al. 1997), namely a strike of $280^{\circ}$, a dipping angle of $35^{\circ}$, with $15 \mathrm{~km}$ length and $9 \mathrm{~km}$ width. Calculations were performed on vertical planes (N1, N2; Fig. 17a) with respect to each fault, considering a $0.26 \mathrm{~cm}$ $\mathrm{yr}^{-1}$ of reverse instead of normal slip for the shallow north-dipping zone.

The calculated Coulomb stress changes resolved for the two major faults are shown in Figs 17(b) and (c), respectively. It is shown that the Psathopyrgos fault is placed in bright areas where the stress changes are positive (Fig. 17b). Similarly, the stress changes due 


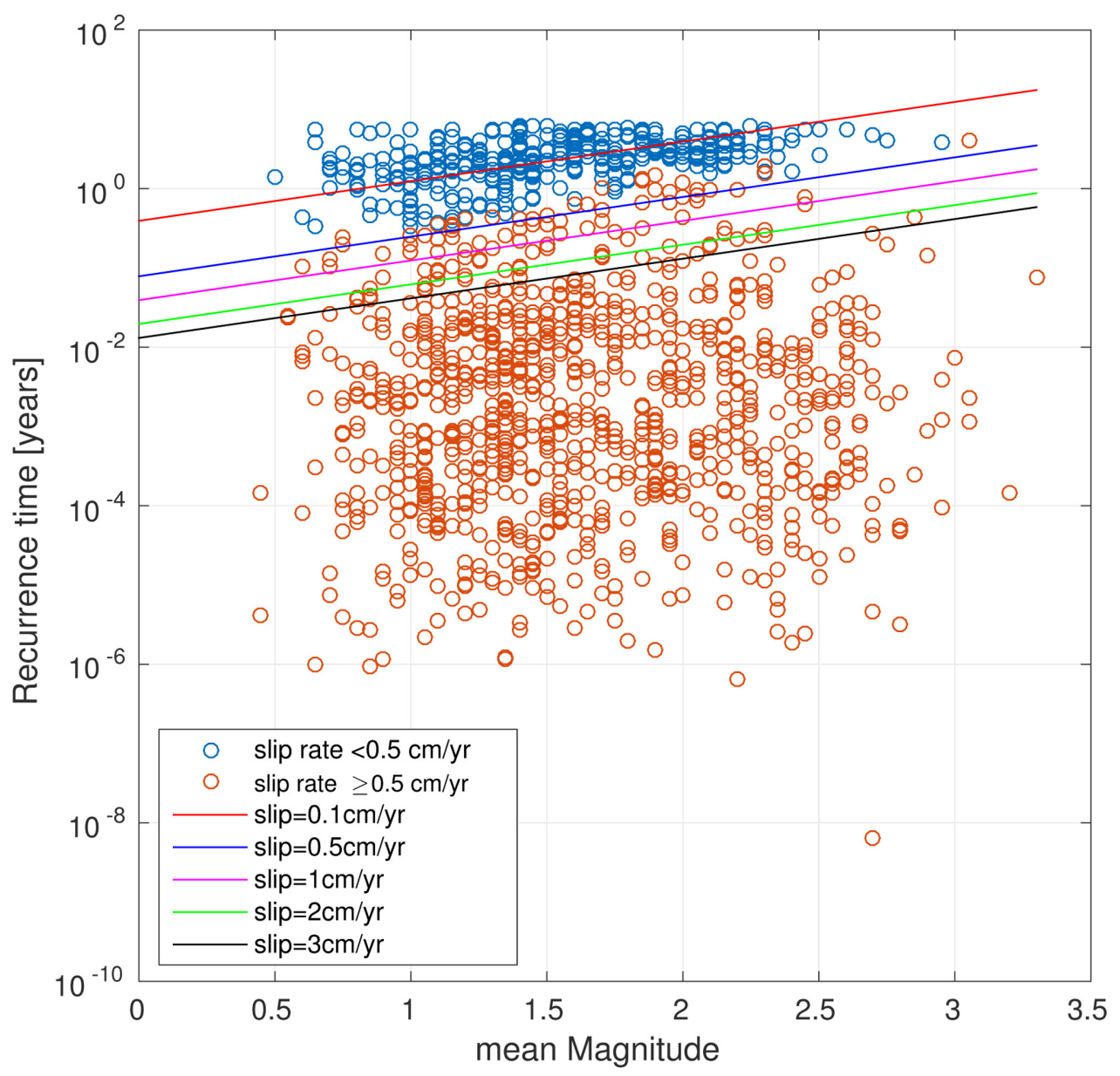

Figure 16. Recurrence intervals against mean magnitude of the doublets. Coloured lines show different loading rates. Doublets with estimated slip rate $<0.5 \mathrm{~cm}$ $\mathrm{yr}^{-1}$ are drawn with blue circles whereas with brown circles are drawn multiplets with $\geq 0.5 \mathrm{~cm} \mathrm{yr}^{-1}$ slip rate.

to the second plane showed that the deeper part of the Aigion fault is located in a bright zone and the upper part on areas where the stresses are decreased (negative values). The Coulomb stress changes indicate that in case of a low-angle normal fault acting as a causative fault, the two major faults should be positively influenced. This should result to a more frequent occurrence of strong events $(M>6.0)$ along the Psathopyrgos and Aigion faults compared to the expected ones from the geodetic measurements (Briole et al. 2000).

In an attempt to calculate the amount of seismic slip, we have taken into account earthquakes with $M \geq 6.0$ that occurred since $1700 \mathrm{AD}$ in the study area, assuming that the catalogue is complete to this level (Ambraseys \& Jackson 1990, 1997; Console et al. 2013). Following a similar approach as in Section 4, we estimated the average slip rate by calculating the total seismic moment and the corresponding radius, considering a constant stress drop. The slip rate was found equal to $0.62 \mathrm{~cm} \mathrm{yr}^{-1}$, almost $45-62$ per cent of the tectonic loading, for an average opening of 1.0-1.4 $\mathrm{cm} \mathrm{yr}^{-1}$. This result does not support the existence of an active low-angle fault in the area, which will lead to more frequent strong events and therefore a higher percentage of seismic slip rate compared to the total slip rate measured geodetically. Thus, we conclude that the slip rate of continuous-type repeaters $\left(0.26 \mathrm{~cm} \mathrm{yr}^{-1}\right)$ indicates aseismic slip, which is equal to $19-26$ per cent of the tectonic loading. The remaining slip, $\sim 15$ per cent, could be accumulated in fault patches associated with earthquakes of intermediate magnitudes $(M<6.0)$ or released aseismically.
Considering the findings of this study and the ones from Mesimeri et al. (2018), we suggest that the continuous-type repeating events, which are spatially correlated and located in the shallow northdipping seismic zone, define the brittle-ductile transition. Repeating earthquakes of continuous type occur on small patches at depths around $10 \mathrm{~km}$ provide evidence for the amount of slip released aseismically. The shallower parts $(3-10 \mathrm{~km})$ of the two main faults (Aigion and Psathopyrgos) are relatively void of seismic activity and could be considered as currently locked. These faults are the most favourable ones for nucleating strong earthquakes.

\section{CONCLUSIONS}

The detailed spatio-temporal analysis of multiplets of repeating events in the western Corinth Gulf contributes to the understanding of the underlying triggering mechanism of microseismic activity in the area. The major finding in this study is the streaks of continuous-type repeating earthquakes formed at $10 \mathrm{~km}$ depth, near the two major faults in the area, indicating that creeping occurs along the brittle-ductile transition zone. The amount of aseismic slip can be quantified by calculating the slip rates of the continuoustype repeaters and was found 26 per cent of the tectonic loading. Another 60 per cent is released seismically considering the earthquakes with $M>6.0$ for the past three centuries. It is suggested that the microseismic activity concentrated on the shallow northdipping zone defines the boundary between the brittle and ductile 


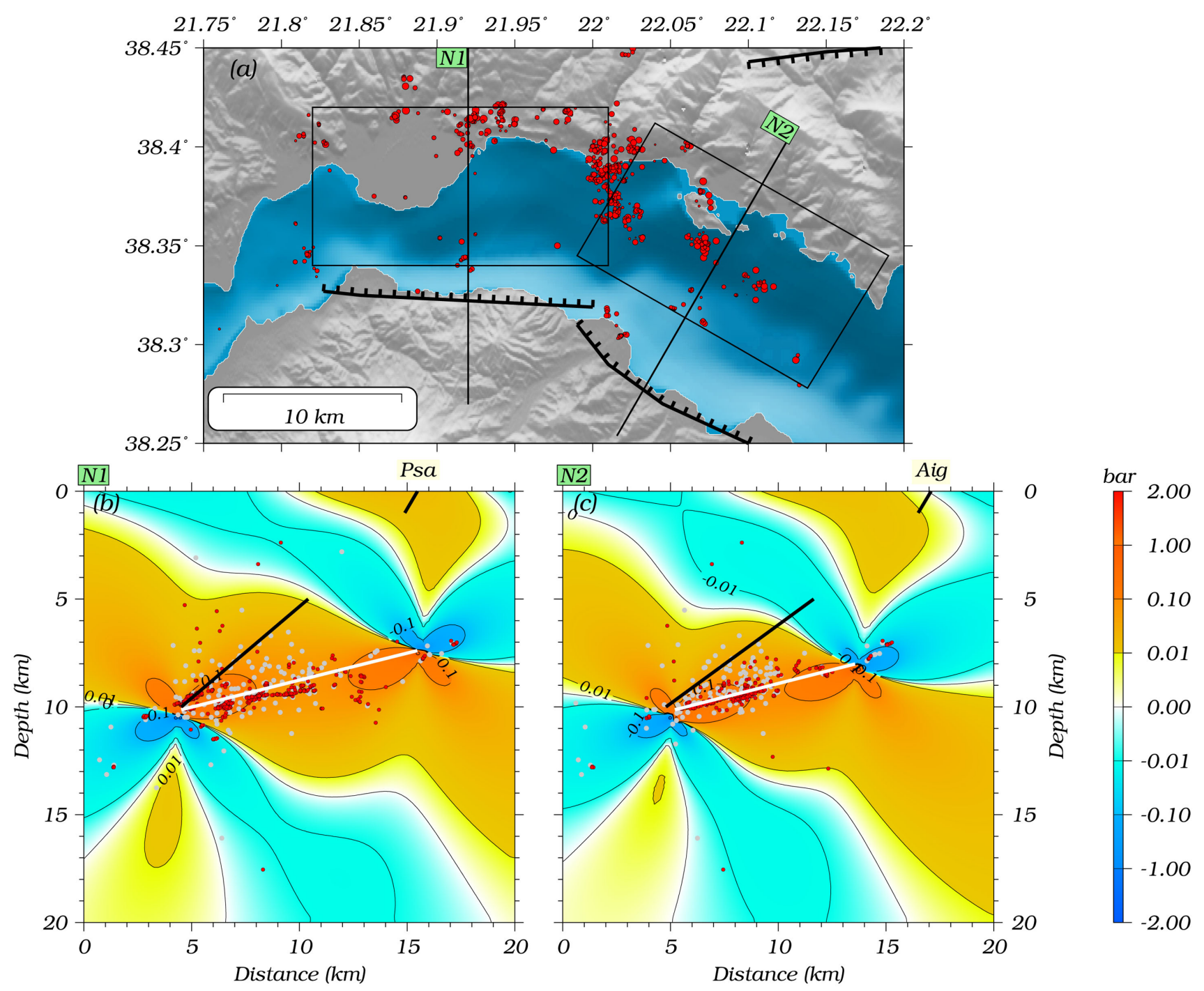

Figure 17. (a) Spatial distribution of the earthquakes belongs to continuous-type repeaters. The boxes show the two horizontal planes. (b and c) Coulomb stress changes by reversing the sense of slip of the shallow seismic zone resolved onto a vertical plane in the directions of N1 and N2 with respect to the two major faults (Psathopyrgos and Aigion), respectively.

layers. The model describing how these continuous-type repeaters nucleate requires small locked patches on stably sliding faults. The surrounding creep loads the small stuck patch according to the slip rate until friction overcomes and the fault patch slips producing a small earthquake. Then, the cycle repeats the same initial conditions triggering the rest of the events in the multiplet in a regularly spaced series (Scholz 2002; Schaff \& Richards 2011). On the other hand, burst-like repeaters, which last from few hours to a few days, are associated with seismic excitations located above the almost horizontal seismic zone and associated with small fault segments which are dipping with high angles. The triggering mechanism of burst-like repeaters is most probably related to fluid intrusion. Future work will focus on updating the catalogue of repeating events by accounting longer periods of seismic activity (2015 and forward) along with an updated relocated catalogue.

\section{ACKNOWLEDGEMENTS}

The authors appreciate the editorial assistance of Prof. E. Hauksson and the constructive comments of two anonymous reviewers. We acknowledge support of this work by the project 'HELPOS-Hellenic
System for Lithosphere Monitoring' (MIS 5002697) which is implemented under the Action 'Reinforcement of the Research and Innovation Infrastructure', funded by the Operational Programme 'Competitiveness, Entrepreneurship and Innovation' (NSRF 20142020) and co-financed by Greece and the European Union (European Regional Development Fund). Some figures were plotted using GMT software (Wessel \& Smith 1998).

\section{REFEREN CES}

Ambraseys, N.N. \& Jackson, J.A., 1990. Seismicity and associated strain of central Greece between 1890 and 1988, Geophys. J. Int., 101, 663-708.

Ambraseys, N.N. \& Jackson, J.A., 1997. Seismicity and strain in the Gulf of Corinth (Greece) since 1694, J. Earthquake Eng., 1(3), 433-474.

Anderlini, L., Serpelloni, E. \& Belardinelli, M.E., 2016. Creep and locking of a low-angle normal fault: insights from the Altotiberina fault in the Northern Apennines (Italy), Geophys. Res. Lett., 43, 4321-4329.

Anooshehpoor, A. \& Brune, J.N., 2001. Quasi-static slip-rate shielding by locked and creeping zones as an explanation for small repeating earthquakes at Parkfield, Bull. seism. Soc. Am., 91, 401-403.

Armijo, R., Meyer, B., King, G.C.P., Rigo, A. \& Paanastassiou, D., 1996. Quaternary evolution of the Corinth Rift and its implications for the Late Cenozoic evolution of the Aegean, Geophys. J. Int., 126, 11-53. 
Avallone, A. et al., 2004. Analysis of eleven years of deformation measured by GPS in the Corinth Rift Laboratory area, C. R. Geosci., 336, 301-311.

Baker, C., Hatzfeld, D., Lyon-Caen, H., Paadimitrious, E. \& Rigo, A., 1997. Earthquake mechanisms of the Adriatic Sea and Western Greece: implications for the oceanic subduction-continental collision transition, Geophys. J. Int., 131, 559-594.

Becker, D., Meier, T., Rische, M., Bohnhoff, M. \& Harjes, H.P., 2006. Spatiotemporal microseismicity clustering in the Cretan region, Tectonophysics, 423, 3-16.

Beeler, N.M., Lockner, D.L. \& Hickman, S.H., 2001. A simple stick-slip and creep-slip model for repeating earthquakes and its implication for microearthquakes at Parkfield, Bull. seism. Soc. Am., 91, 1797-1804.

Bernard, P. et al., 1997. The $\mathrm{M}_{\mathrm{s}}=6.2$ June 15, 1995 Aigion earthquake (Greece): evidence for low angle, J. Seismol., 1, 131-150.

Bernard, P. et al., 2006. Seismicity, deformation and seismic hazard in the western rift of Corinth: new insights from the Corinth Rift Laboratory (CRL), Tectonophysics, 426, 7-30.

Beroza, G.C., Cole, A.T. \& Ellsworth, W.L., 1995. Stability of coda wave attenuation during the Loma-Prieta, California, earthquake sequence, $J$. geophys. Res., 100, 3977-3987.

Billiris, H. et al., 1991. Geodetic determination of tectonic deformation in central Greece from 1900 to 1988, Nature, 350, 124-129.

Bohnhoff, M., Wollin, C., Domigall, D., Kuperoch, L., Martinez-Garzon, P., Kwiate, G. \& Malin, E., 2017. Repeating Marmara Sea earthquakes: indication for fault creep, Geophys. J. Int., 210, 332-339.

Briole, P. et al., 2000. Active deformation of the Corinth rift, Greece: results from repeated Global Positioning System surveys between 1990 and 1995, J. geophys. Res., 105, 25 605-25 625

Chen, K.H., Bürgmann, R. \& Nadeau, R.M., 2013. Do earthquakes talk to each other? Triggering and interaction of repeating sequences at Parkfield, J. geophys. Res., 118, 165-182.

Chiaraluce, L., Chiarabba, C., Collettini, C., Piccinini, D. \& Coo, M., 2007. Architecture and mechanics of an active low-angle normal fault: Alto Tiberina Fault, northern Apennines, Italy, J. geophys. Res., 112(B10).

Chousianitis, K., Ganas, A. \& Evangelidis, C.P., 2015. Strain and rotation rate patterns of mainland Greece from continuous GPS data and comparison between seismic and geodetic moment release, J. geophys. Res., 120, 3909-3931.

Clarke, P.J. et al., 1998. Crustal strain in Greece from repeated GPS measurements in the interval 1989-1997, Geophys. J. Int., 135, 195-214.

Console, R., Carluccio, R., Papadimitriou, E. \& Karakostas, V., 2015. Synthetic earthquake catalogs simulating seismic activity in the Corinth Gulf, Greece, fault system, J. geophys. Res., 120, 326-343.

Console, R., Falcone, G., Karakostas, V., Murru, M., Papadimitriou, E. \& Rhoades, D., 2013. Renewal models and coseismic stress transfer in the Corinth Gulf, Greece, fault system, J. geophys. Res., 118, 3655-3673.

Deng, J. \& Sykes, L.R., 1997. Evolution of the stress field in southern California and triggering of moderate-size eartquakes: a 200 -year perspective, J. geophys. Res., 102, 9859-9886.

Dominguez, L.A., Taira, T. \& Santoyo, M.A., 2016. Spatiotemporal variations of characteristic repeating earthquake sequences along the Middle America Trench in Mexico, J. geophys. Res., 121, 8855-8870.

Dublanchet, P., Godano, M. \& Bernard, P., 2015. Inferring fault mechanical conditions from the source parameters of a complex microseismic multiplet in the Corinth rift, Greece, J. geophys. Res., 120, 7655-7682.

Erickson, L., 1986. User's manual for DIS3D: a three dimensional dislocation program with applications to faulting in the Earth, M.Sc. Dissertation, Stanford University, $167 \mathrm{p}$.

Geller, R.J. \& Mueller, C.S., 1980. Four similar earthquakes in central California, Geophys. Res. Lett., 7, 821-824.

Got, J.L., Fréchet, J. \& Klein, F.W., 1994. Deep fault plane geometry inferred from multiplet relative relocation beneath the south flank of Kilauea, $J$. geophys. Res., 99, 15 375-15 386.

Hanks, T.C. \& Kanamori, H., 1979. A moment magnitude scale, J. geophys. Res., 84, 2348-2350.

Hatzfeld, D., Karakostas, V., Ziazia, M., Kassaras, I., Papadimitriou, E., Makropoulos, K., Voulgaris, N. \& Papaioannou, V., 2000. Microseismicity and faulting geometry in the Gulf of Corinth (Greece), Geophys. J. Int., 141, 438-456.

Hauksson, E. \& Shearer, P. 2005. Southern California hypocenter relocation with waveforms cross-correlation, part 1: results using the double difference method, Bull. seism. Soc. Am., 95, 896-903.

Igarashi, T., Matsuzawa, T. \& Hasegawa, A., 2003. Repeating earthquakes and interplate aseismic slip in the northeastern Japan subduction zone, $J$. geophys. Res., 108.

Jacobs, K.M., Smith, G.C.E., Savage, M.K. \& Zhuang, J., 2013. Cumulative rate analysis (CURATE): a clustering algorithm for swarm dominated catalogs, J. geophys. Res., 118, 553-569.

Johnson, L.R. \& Nadeau, R.M., 2002. Asperity model of an earthquake: static problem, Bull. seism. Soc. Am., 92, 672-686.

Kagan, Y.Y. \& Jackson, D.D., 1991. Long-term earthquake clustering, Geophys. J. Int., 104, 117-134.

Kanu, C.O., Snieder, R. \& O' Connell, D., 2013. Estimation of velocity change using repeating earthquakes with different locations and focal mechanisms, J. geophys. Res., 118, 2905-2914 .

Kapetanidis, V. et al., 2015. The 2013 earthquake swarm in Helike, Greece: seismic activity at the root of old normal faults, Geophys. J. Int., 202, 2044-2073.

Kaviris, G., Spingos, I., Kapetanidis, V., Papadimitriou, P., Voulgaris, N. \& Makropoulos, K., 2017. Upper crust seismic anisotropy study and temporal variations of shear-wave splitting parameters in the Western Gulf of Corinth (Greece) during 2013, Phys. Earth planet. Inter., 269, 148-164.

Keilis-Borok, V.I., 1959. On the estimation of the displacement in an earthquake source and of source dimensions, Ann. Geofis., 12, 205-214.

Kiratzi, A. et al., 2008. The April 2007 earthquake swarm near Lake Trichonis and implications for active tectonics in western Greece, Tectonophysics, 452, 51-65.

Lambotte, S. et al., 2014. Reassessment of the rifting process in the Western Corinth Rift from relocated seismicity, Geophys. J. Int., 197, 1822-1844.

Lecomte, E., Le Pourhiet, L. \& Lacombe, O., 2012. Mechanical basis for slip along low-angle normal faults, Geophys. Res. Lett., 39, 1-6.

Lyon-Caen, H., Papadimitriou, P., Deschamps, A., Bernard, P., Makropoulos, K., Pacchiani, F. \& Patau, G., 2004. First results of the CRLN seismic network in the western Corinth Rift: evidence for old-fault reactivation, Geoscience, 336, 343-351.

Makropoulos, K., Kaviris, G. \& Kouskouna, V., 2012. An updated and extended earthquake catalogue for Greece and adjacent areas since 1900, Nat. Hazards Earth Syst. Sci., 12, 1425-1430.

Mangira, O., Vasiliadis, G. \& Papadimitriou, E., 2017. Application of a linked stress release model in Corinth Gulf and Central Ionian Islands (Greece), Acta Geophys., 65, 517-531.

Mesimeri, M., Karakostas, V., Papadimitriou, E., Schaff, D. \& Tsaklidis, G., 2016. Spatio-temporal properties and evolution of the 2013 Aigion earthquake swarm (Corinth Gulf, Greece), J. Seismol., 20, 595-614.

Mesimeri, M., Karakostas, V., Papadimitriou, E., Tsaklidis, G. \& Jacobs, K., 2018. Relocation of recent seismicity and seismotectonic properties in the Gulf of Corinth (Greece), Geophys. J. Int., 212, 1123-1142.

Nadeau, R.M. \& Johnson, L.R., 1998. Seismological studies at Parkfield VI: moment release rates and estimates of source parameters for small repeating earthquakes, Bull. seism. Soc. Am., 88, 790-814.

Nadeau, R.M. \& McEvilly, T.V., 1999. Fault slip rates at depth from recurrence intervals of repeating microearthquakes, Science, 285, 718-721.

Nadeau, R.M. \& McEvilly, T.V., 2004. Periodic pulsing of characteristic microearthquakes on the San Andreas fault, Science, 303, 220-222.

Nadeau, R.M., Michelini, A., Uhrhammer, R.A., Dolenc, D. \& McEvilly, T., 2004. Detailed kinematics, structure and recurrence of micro-seismicity in the SAFOD target region, Geophys. Res. Lett., 31, 12-15.

Papadimitriou, E., Karakostas, V., Mesimeri, M., Chouliaras, G. \& Kouroulas, Ch., 2017. The $\mathrm{M}_{\mathrm{w}} 6.517$ November 2015 Lefkada (Greece) earthquake: structural interpretation by means of the aftershock analysis, Pure appl. Geophys., 174, 3869-3888.

Papazachos, B.C., Papadimitriou, E.E., Kiratzi, A.A., Papazachos, C.B. \& Louvari, E. K., 1998. Fault plane solutions in the Aegean Sea and the 
surrounding area and their tectonic implication, Boll. Geofis. Teor. Appl., 39, 199-218.

Papazachos, B.C. \& Papazachou, K., 2003. The Earthquakes of Greece, Ziti Publications.

Peng, Z. \& Ben-Zion, Y., 2005. Spatiotemporal variations of crustal anisotropy from similar events in aftershocks of the 1999 M7.4Izmit and M7.1 Duzce, Turkey, earthquake sequences, Geophys. J. Int, 160(3), $1027-1043$.

Rigo, A., Lyon-Caen, H., Armijo, R., Deschamps, A., Hatzfeld, D., Makropoulos, K., Papadimitriou, P. \& Kassaras, I., 1996. A microseismic study in the western part of the Gulf of Corinth (Greece): implications for large-scale normal faulting mechanisms, Geophys. J. Int., 126, 663-688.

Rubin, A.M., Gillard, D. \& Got, J.J., 1999. Streaks of microearthquakes along creeping faults, Nature, 400, 635-641.

Rubinstein, J.L., Ellsworth, W.L., Chen, K.H. \& Uchida, N., 2012. Fixed recurrence and slip models better predict earthquake behavior than the time-and slip-predictable models: 1 . Repeating earthquakes, J. geophys. Res., 117, 1-23.

Rudziński, Ł., Mirek, J. \& Lizurek, G., 2017. Identification of seismic doublets occurred on Rudna mine, Poland. Acta Geophys., 65, 287-298.

Sammis, C.G. \& Rice, J.R., 2001. Repeating earthquakes as low-stress-drop events at a border etween locked and creeping fault patches, Bull. seism. Soc. Am., 91, 532-537.

Schaff, D.P, Beroza, G.C. \& Shaw, B.E., 1998. Postseismic response of repeating aftershocks, Geophys. Res. Lett., 25, 4549-4552.

Schaff, D.P. \& Beroza, G.C., 2004. Coseismic and postseismic velocity changes measured by repeating earthquakes, J. geophys. Res., 109(B10).

Schaff, D.P., Bokelmann, G.H.R., Beroza, G.C., Waldhauser, F. \& Ellsworth, W.L., 2002. High-resolution image of Calaveras Fault seismicity, J. geophys. Res., 107, 1-16.

Schaff, D.P., Bokelmann, G.H.R., Ellsworth, W.L., Zanzerkia, E., Waldhauser, F. \& Beroza, G., 2004. Optimizing correlation techniques for improved earthquake location, Bull. seism. Soc. Am., 94, 705-721.

Schaff, D.P. \& Richards, P.G., 2004. Repeating seismic events in China, Science, 303, 1176-1179.

Schaff, D.P. \& Richards, P.G., 2011. On finding and using repeating seismic events in and near China, J. geophys. Res., 116, 1-20.

Schaff, D.P. \& Waldhauser, F., 2005. Waveform cross-correlation-based differential travel-time measurements at the northern California seismic network, Bull. seism. Soc. Am., 95, 2446-2461.

Scholz, C.H., 2002. The Mechanics of Earthquake and Faulting, 2nd edn, Cambridge Univ. Press.
Scordilis, E.M., Kementzetzidou, D. \& Papazachos, B.C., 2016. Local magnitude calibration of the Hellenic Unified Seismic Network, J. Seismol., 20, 319-332.

Shapiro, S.A., 2015. Fluid-Induced Seismicity, 1st edn, Cambridge Univ. Press.

Templeton, D.C., Nadeau, R.M. \& Burgmann, R., 2008. Behavior of repeating earthquake sequences in Central California and the implications for subsurface fault creep, Bull. sesim. Soc. Am., 98, 52-65 .

Uchida, N., Matsuzawa, T. \& Hasegawa, A., 2003. Interplate quasi-static slip off Sanriku, NE Japan, estimated from repeating earthquakes, Geophys. Res. Lett., 30(15).

Uchida, N., Matsuzawa, T., Hasegawa, A. \& Igarashi, T., 2005. Recurrence intervals of characteristic M4.8 \pm 0.1 earthquakes off-Kamaishi, NE Japan - comparison with creep rate estimated from small repeating earthquake data, Earth planet. Sci. Lett., 233, 155-165.

Valoroso, L., Chiaraluce, L., Di Stefano, R. \& Monachesi, G., 2017. Mixedmode slip behaviour of the Altotiberina low-angle normal fault system (Northern Apennines, Italy) through high-resolution earthquake locations and repeating events, J. geophys. Res., 85, 1-21.

Valoroso, L., Chiaraluce, L., Piccinini, D., Di Stefano, R., Schaff, D. \& Waldhauser, F., 2013. Radiography of a normal fault system by 64,000 high-precision earthquake locations: the 2009 L'Aquila (central Italy) case study, J. geophys. Res., 118, 1156-1176.

Vidale, J.E., Ellsworth, W.L., Cole, A. \& Marone, C.J., 1994. Variations in rupture process with recurrence interval in a repeated small earthquake, Nature, 368, 624-626.

Waldhauser, F. \& Ellsworth, W.L., 2002. Fault structure and mechanics of the Hayward Fault, California, from double-difference earthquake locations, J. geophys. Res., 107(B3), ESE 3-1-ESE 3-15.

Waldhauser, F. \& Schaff, D.P., 2008. Large-scale relocation of two decades of Northern California seismicity using cross-correlation and doubledifference methods, J. geophys. Res., 113, 1-15.

Wessel, P. \& Smith, W.H.F., 1998. New, improved version of the generic mapping tools released, EOS, Trans. Am. Geophys. Un., 79, 579.

Weston, J. \& Shirzaei, M., 2016. Combining GPS and repeating earthquakes for a high resolution analysis of subduction zone coupling, Tectonophysics, 667,37-47.

Yao, D., Walter, J.I., Meng, X., Hobbs, T.E., Peng, Z., Newman, A.V., Schwartz, S.Y. \& Protti, M., 2017. Detailed spatio-temporal evolution of microseismicity and repeating earthquakes following the $2012 M_{\mathrm{W}} 7.6$ Nicoya earthquake, J. geophys. Res., 122(1), 524-542. 


\section{APPENDIX}

Table A1. Characteristics of the identified multiplets.

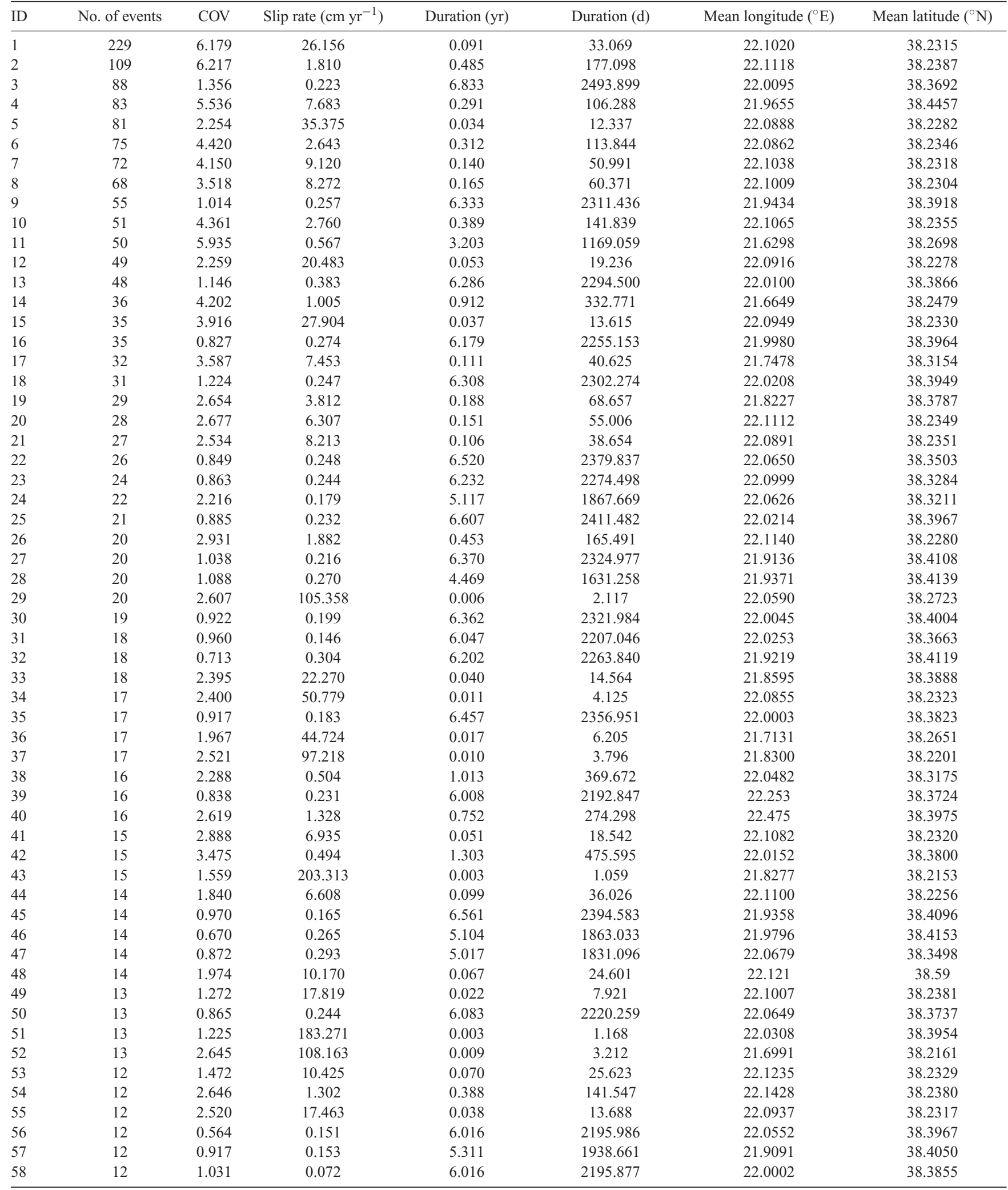


Table A1. Continued

\begin{tabular}{|c|c|c|c|c|c|c|c|}
\hline ID & No. of events & $\mathrm{COV}$ & Slip rate $\left(\mathrm{cm} \mathrm{yr}^{-1}\right)$ & Duration (yr) & Duration (d) & Mean longitude $\left({ }^{\circ} \mathrm{E}\right)$ & Mean latitude $\left({ }^{\circ} \mathrm{N}\right)$ \\
\hline 59 & 12 & 2.997 & 0.130 & 5.545 & 2023.925 & 21.9095 & 38.3399 \\
\hline 60 & 12 & 1.542 & 0.150 & 5.289 & 1930.339 & 22.0148 & 38.3033 \\
\hline 61 & 12 & 1.169 & 574.348 & 0.001 & 0.365 & 22.0261 & 38.3967 \\
\hline 63 & 12 & 0.957 & 0.210 & 5.594 & 2041.920 & 21.8761 & 38.4314 \\
\hline 64 & 12 & 0.833 & 0.132 & 4.986 & 1820.036 & 21.8057 & 38.3425 \\
\hline 65 & 12 & 0.999 & 9.682 & 0.067 & 24.346 & 21.6364 & 38.2674 \\
\hline 68 & 11 & 1.164 & 0.206 & 5.854 & 2136.820 & 22.0043 & 38.3602 \\
\hline 69 & 11 & 0.451 & 0.179 & 5.623 & 2052.322 & 22.0179 & 38.3612 \\
\hline 70 & 11 & 1.894 & 0.181 & 4.719 & 1722.399 & 22.0048 & 38.3165 \\
\hline 71 & 11 & 2.797 & 6.340 & 0.259 & 94.353 & 21.9665 & 38.4214 \\
\hline 72 & 11 & 2.656 & 0.281 & 4.005 & 1461.789 & 22.0926 & 38.3101 \\
\hline 73 & 11 & 0.885 & 840.865 & 0.001 & 0.256 & 22.0097 & 38.4005 \\
\hline 78 & 10 & 0.815 & 0.149 & 5.189 & 1894.095 & 22.0226 & 38.3543 \\
\hline 79 & 10 & 0.762 & 0.072 & 6.077 & 2218.069 & 21.9207 & 38.3967 \\
\hline 80 & 10 & 0.961 & 0.108 & 4.983 & 1818.832 & 21.9973 & 38.4197 \\
\hline 81 & 10 & 1.333 & 0.229 & 4.513 & 1647.318 & 21.9391 & 38.4085 \\
\hline 82 & 10 & 2.498 & 1.135 & 0.334 & 121.764 & 22.1184 & 38.2906 \\
\hline 83 & 10 & 1.164 & 204.466 & 0.002 & 0.584 & 22.0011 & 38.3408 \\
\hline 84 & 10 & 0.594 & 0.106 & 5.743 & 2096.013 & 21.8084 & 38.4012 \\
\hline 85 & 10 & 0.855 & 0.345 & 5.441 & 1985.965 & 21.8632 & 38.4141 \\
\hline 86 & 10 & 1.609 & 0.124 & 3.301 & 1204.902 & 21.8151 & 38.4085 \\
\hline 87 & 10 & 0.875 & 12.760 & 0.039 & 14.089 & 21.6673 & 38.2477 \\
\hline 88 & 10 & 2.523 & 0.197 & 2.670 & 974.696 & 21.7930 & 38.3415 \\
\hline 89 & 10 & 1.046 & 13.487 & 0.025 & 9.016 & 21.6342 & 38.3087 \\
\hline
\end{tabular}

